\title{
MÉDICOS, CIRUJANOS Y CURANDEROS EN CÓRDOBA DURANTE LA SEGUNDA MITAD DEL SIGLO XV
}

\author{
MARGARITA CABRERA \\ Universidad de Córdoba
}

\begin{abstract}
SUMARIO
I. La lucha contra la enfermedad.- II. La formación de los médicos.III. La transmisión de los saberes médicos.- IV. Los empíricos.
\end{abstract}

El estudio de la medicina bajomedieval ha recibido una moderada atención por parte de los estudiosos hasta hace pocos años. Aunque no faltan publicaciones sobre el particular, hay otras épocas de nuestra historia que han ejercido sobre ellos mayor atractivo, como es el caso de la España islámica altomedieval o bien la época renacentista'. Ello se debe, en primer

\footnotetext{
${ }^{1}$ Contamos, no obstante, con aportaciones valiosas, en primer lugar, de carácter general y, entre ellas, el libro de L. GARCía BALLESTER, Historia social de la Medicina en la España de los siglos XIII al XVI, Madrid, 1976, así como su amplio capítulo dedicado a la Medicina en el vol. XVI de la Historia de España dirigida por R. Menéndez Pidal, pp. 597-656. Lo mismo puede decirse de la obra de L. GRANJEL, Medicina española antigua y medieval, I volumen de la Historia General de la Medicina Española, publicada en Salamanca en 1981. Es aún más útil, en relación con la época final de la Edad Media el volumen segundo de la citada obra de Granjel: La Medicina española renacentista, Salamanca, 1980, 289 pp. También, la obra de I. de la VILla, Los médicos y la medicina en la época de los Reyes Católicos, Valladolid, 1939 así como los trabajos de J.R. ZARAGOZA RUBiRA, entre ellos Aspectos médicos de la España del siglo XV en el 'Viaje' de Jerónimo Müntzer, "Medicina Española", LI, 298, Valencia, 1964, pp. 128-136 y "Aspectos médicos de la España del siglo XV según el viaje de León Rosmitha en Medicina Española, LIII, 311, Valencia, 1965, pp. 128-136. También el estudio de ZUBIR VIDAL, La Medicina en la época de los Reyes Católicos, Zaragoza, 1957. Otros trabajos útiles son los de: M.V. Amasuno, El libro de Medicina de Bernardo de Gordonio. Contribución al 
lugar, a los grandes logros conseguidos en el campo de la medicina en ambas etapas de nuestra historia. Pero sobre todo es una consecuencia de la mayor abundancia de tratados de medicina elaborados en ellas. Esa circunstancia permite una aproximación más fácil al tema de los conocimientos médicos y facilita, sobre todo, el estudio de la tradición médica, singularmente la que tenía su fundamento en los grandes teóricos de la Antigüedad, cuya influencia puede rastrearse más fácilmente estudiando de forma comparativa ese tipo de obras. Aun así, parece evidente que ha aumentado el interés por el estudio de los últimos siglos de la Edad Media, respecto de los cuales se ha abordado la cuestión refiriéndola a ámbitos geográficos más concretos, dentro de la geografía peninsular. En particular, la Corona de Aragón cuenta con trabajos extraordinariamente meritorios. Incluso se han hecho interesantes estudios a escala local, basándose, en esos casos, no tanto en los tratados de medicina sino más bien en las fuentes documentales de la época, a partir de las cuales podemos conocer, a veces, numerosos pormenores sobre las prácticas médicas habituales entonces ${ }^{2}$.

estudio del lenguaje médico español del siglo XV. Tesis doctoral, Salamanca, 1972; J.L. BROUARD URIARTE, Médicos, cirujanos, barberos y algebristas castellanos del siglo XV, en "Cuadernos de Historia de la Medicina Española", XI (Salamanca, 1972), pp. 239-253; L.S. Granjel, La medicina española en la época de los Reyes Católicos, Medicina e Historia, $2^{\mathrm{a}}$ época, $\mathrm{n}^{\mathrm{0}}$ 1, Barcelona, 1971; J.M. JIMÉNEZ MUÑOZ, Noticia sobre pestes en el reino de Castilla (1478-1494), "Cuadernos de Historia de la Medicina española", XII (Salamanca, 1974), pp. 347-356. Una aportación reciente es la de J. LOSANA MÉNDEZ, La sanidad en la época del descubrimiento de América, Madrid, Cátedra, 1994. Aporta una buena información y una excelente bibliografía, aunque referida, en general, al siglo XVI, a pesar de su título. Son sumamente interesantes en relación con la Baja Edad Media algunas de las aportaciones contenidas en la obra: Santé, médecine et assistance au Moyen Âge ("110 Congrès National des Sociétés Savantes"), París, 1985. Sobre figuras representativas de médicos de la época, ver: J. TORRES FONTES, Un médico alfonsí: Maestre Nicolás, "Murgetana", VI (1954), pp. 9-16; También los trabajos de M. Alonso CORTÉs, Dos médicos de los Reyes Católicos, "Hispania", XI (1951), pp. 607-57 y A. de la TORRE Y DEL CERRO, Un médico de los Reyes Católicos. Lorenzo Badoc, "Hispania", IV (1944), pp. 66-72. Una aportación reciente es la de M.V. Amasuno SÁrRaga, Alfonso Chirino, un médico de monarcas castellanos, Consejería de Cultura y Turismo de la Junta de Castilla y León, 1993, 177 pp.; los trabajos contenidos en Medicina y sociedad: Curar y sanar en la España de los siglos XIII al XVI, coordinado por M.E. GonZÁlez DE Fauve, Buenos Aires, 1996.

${ }^{2}$ A. CARdoner y Planas, Historia de la medicina a la Corona d'Aragó, 1162-1479, Barcelona, Ed. Scientia, 1973. L. COMENGE Y FERRER, La medicina en el reino de Aragón, Valladolid, 1979. M.C. GARCÍA HERRERO, Administrar del parto y recibir la criatura: aportación al estudio de obstetricia bajomedieval. En "Aragón en la Edad Media", VIII ("Homenaje al Prof. D. Antonio Ubieto Arteta"), Zaragoza, 1989, pp. 283-292. J. EsPLUGUES REQUENA, Tradición farmacológica valenciana. Sus momentos estelares, Valencia, 1975. A. GARCíA, Tres bibliotecas de médicos valencianos renacentistas (Luis Alzañiz, Pere Pintor y Pere Marti), "Asclepio", XXVI-XXVII, 1974-75, pp. 527-46. L. GARCÍA BALLESTER, Aproximación a la la historia de la Medicina bajomedieval en Valencia, "Cuadernos de Historia de la 
Dentro de la Corona de Castilla hay regiones que han recibido un tratamiento relativamente abundante del tema, como sucede en el caso de Murcia ${ }^{3}$.

Pero en relación con el objeto al que se refiere este trabajo, la ciudad de Córdoba y su entorno, las aportaciones al tema, con algunas excepciones notables, han sido muy modestas. En ese sentido, el contraste con los estudios existentes sobre la medicina cordobesa en la época de dominio islámico es muy notorio y fácilmente explicable. Aun así, contamos con algunas aportaciones que, aunque muy desiguales, constituyen, no obstante, un punto de partida, aunque no en todos los casos se refieren a la época que ahora nos interesa estudiar ${ }^{4}$. Algunas menciones incidentales de instituciones hospitalarias cordobesas de la Baja Edad Media aparecidas en obras muy diversas no han contribuido tampoco a aumentar nuestros conocimientos ${ }^{5}$.

Medicina Española", VIII (Salamanca, 1969), pp. 45-78. De este mismo autor, ver también: La cirugía en la Valencia del siglo XV, "Cuadernos de Historia de la Medicina Española", VI (1967), pp. 155-171 y El privilegio concedido en 1478 a los cirujanos de Valencia para disecar cadáveres, "Actas del III Congreso Nacional de Historia de la Medicina", II, Valencia, 1969, pp. 73-76. Referente a una época anterior es el estudio de C. GUILERÉ, Le milieu médical géronais au XIV siècle, en "Santé, Médecine et assistance au Moyen Age" (" $110^{\mathrm{e}}$ Congrès National des Sociétés Savantes"), París, 1985, pp. 263-281. Otros estudios de interés son los de F. ZUBIRI VIDAL, Miguel Zurita, médico aragonés del siglo XV, "III Jornadas Médicas Aragonesas, Actas", Zaragoza, 1959, pp. 351-354 y Miguel Zurita de Alfaro, "Zaragoza", XXIV, (Zaragoza, 1966), pp. 165-170. En relación con Andalucía, ver: J. RIERA, Maestro Pedro, hernista sevillano del siglo XV, "IV Congreso Español de Historia de la Medicina, Actas", I, Granada, 1975, pp. 61-62 y, del mismo autor: Dos parteras sevillanas (siglo XV), "IV Congreso Español de Historia de la Medicina, Actas", I, Granada, 1975, pp. 63-67. Un libro a tener en cuenta es también el de G. BEaujouAn, Médécine humaine et veterinaire a la fin du Moyen Âge, Droz, 1966.

${ }^{3}$ En este apartado cabría insertar el trabajo de J. QueSADA SANZ, Algunos aspectos de la Medicina en Murcia durante la época de los Reyes Católicos, "Murgetana", 6 (Murcia, 1954), pp. 53-98 y los numerosos y clarificadores estudios debidos al profesor J. TORRES FONTES, Datos y documentos para una historia de la farmacia en Murcia. El boticario Alonso de Alves, "Apotheca", 2 (1960), pp. 26-28; De Historia médica murciana, I: Los médicos, Murcia, 1980; De Historia médica murciana, II: Las epidemias, Murcia, 1981; El saludador, en "Homenaje a José Ballester", Murcia, 1973; Los boticarios murcianos en el reinado de los Reyes Católicos. "Apotheca", 1 (Murcia, 1959); Los médicos murcianos en el siglo XV, "Miscelánea Medieval Murciana", 1 (1973), pp. 203-267 y Contienda entre boticarios, "Estampas de la vida murciana en la época de los Reyes Católicos", Murcia, 1984, pp. 209-215.

${ }^{4}$ Véanse, entre otros, los trabajos de G. SALDAN̄a SiCILIA, Monografía histórico médica de los hospitales de Córdoba, Córdoba, 1935, y G. GARCía GonZÁlez, Historia de la asistencia psiquiátrica en Córdoba hasta el primer tercio del siglo XX, Córdoba, Diputación Provincial, 1983. A. García Del Moral, El Hospital mayor de San Sebastián de Córdoba. Cinco siglos de asistencia médico-sanitaria institucional (1363-1816), Córdoba, Diputación Provincial, 1984. M.C. BlaSCo ORdóNEZ, Cuidados y cuidadores en la Historia de Córdoba. Evolución de la Enfermería, Córdoba, Diputación Provincial, 1990.

${ }^{5}$ Así el manuscrito Noticia auténtica de los hospitales que ha habido y de los que duran en esta Ciudad de Córdoba, mencionado por GARCía GONZÁLEZ, op. cit., p. 13 nº 4. 
La más famosa de estas instituciones era el Hospital de la Caridad de Jesucristo, situado en la Plaza del Potro, que ejercía una gran labor asistencial no sólo en relación con los enfermos, sino también en otro tipo de empresas humanitarias, como, por ejemplo, proporcionando medios económicos y de otro tipo para la liberación de los cautivos cristianos en el reino de Granada.

En todo caso, el ejercicio de la profesión médica en Córdoba durante la Baja Edad Media es prácticamente desconocido. Sin embargo, son relativamente abundantes las noticias que aparecen en los protocolos notariales referentes a quienes practicaban la medicina en la ciudad. El presente trabajo pretende ser, precisamente, una modesta aportación al tema sin otra finalidad que la de ofrecer una serie de testimonios espigados a través de la lectura atenta de los protocolos cordobeses y es anuncio de una obra de mayor envergadura que tenemos en preparación ${ }^{6}$. A través de esos documentos conocemos algunas veces determinadas circunstancias o ciertos actos médicos más o menos rutinarios que en aquellos tiempos solían provocar la redacción de un acta notarial ${ }^{7}$. Otra clase de intervenciones - singularmente aquellas que eran arriesgadas - también han dejado su rastro en ese tipo de documentos y constituyen, a veces, preciosos testimonios que ponen de manifiesto las dificultades que tenía aquella sociedad para luchar contra las enfermedades y los medios rutinarios y con frecuencia ineficaces que empleaba para combatirlas. Por otro lado y debido a su propia naturaleza, son mucho más frecuentes las menciones de actos médicos relacionados con prácticas quirúrgicas que aquellos que se refieren al ejercicio clínico de la medicina. Y son numerosas las menciones incidentales de médicos, físicos, cirujanos, curanderos, barberos y sangradores a través de las cuales se puede intentar reconstruir el ambiente en que vivían los

\footnotetext{
${ }^{6}$ Se citará siempre el Archivo Histórico Provincial de Córdoba (AHPC), Protocolos Notariales (PN) y a continuación el número de escribanía, seguido -y separado por un guióndel legajo correspondiente. De las dos numeraciones que se refieren a esos legajos hemos optado por incluir entre paréntesis la más reciente.

${ }^{7}$ Así sucedía habitualmente, por ejemplo, con operaciones de circuncisión motivadas por procesos infecciosos. De ellas hay abundantes ejemplos en los registros de protocolos. Junto a los muchísimos casos que pueden estudiarse consultando ese tipo de documentación, ver el estudio, referente a época más tardía, debido a J.C. GÓMEZ-MENOR FUENTES, Dos casos de circuncisión por motivos terapéuticos y otros datos sobre médicos toledanos de los siglos XVI y XVII. "Cuadernos de Historia de la Medicina Española", XIV (Salamanca, 1975), pp. 191207.
} 
profesionales de la medicina en sus diferentes especialidades, su capacidad económica y su implicación en la vida social y política de la época.

\section{LA LUCHA CONTRA LA ENFERMEDAD}

Quienes vivían en el siglo XV estaban expuestos a la mayor parte de las enfermedades que hoy día siguen afectando al género humano. Muchas de ellas eran conocidas con otros nombres, que hacen más difícil identificarlas con precisión. Sin embargo, en una buena parte de los casos, la descripción, generalmente somera, que suele hacerse del cuadro clínico nos permite conjeturar con bastante aproximación de qué enfermedad podía tratarse. En otras ocasiones, y tal como ha sido frecuente hasta los grandes avances médicos del último siglo y medio, a muchas de las enfermedades se las citaba solamente por sus síntomas, lo cual no nos permite conocer la naturaleza exacta del mal que los producía.

Por otra parte, a lo largo de la historia de la Humanidad e, incluso, simplemente durante los siglos medievales el cuadro de enfermedades que afectaron habitualmente al hombre experimentó una evolución que, aunque difícil de observar, es perfectamente visible en algunos casos. Es conocida, por otro lado, la especial incidencia que algunas de ellas tuvieron en determinadas épocas. Por ejemplo, está demostrada la presencia creciente de la lepra en Europa a partir de las Cruzadas hasta el punto de que ha podido hablarse de una verdadera "importación" de esa enfermedad a Occidente a partir del siglo XII. Es conocida también la extensión de la peste bubónica a partir del siglo XIV, lo cual se ha relacionado también con la penetración en Europa de la rata negra, de origen asiático, que se produjo, al parecer a partir del primero de los dos siglos citados.

De todas formas, la documentación de la época y también los tratados médicos que se escribieron en ella permiten citar como habituales numerosas enfermedades de las cuales algunas, en concreto, casi han desaparecido en nuestros días. La primera de ellas es la lepra. Los contemporáneos suelen denominarla "lepra de Sant Lázaro" y así aparece tanto en la documentación como en los tratados médicos de la época ${ }^{8}$. La documentación estudiada nos ofrece algunos ejemplos de enfermos leprosos en Córdoba. Así, en 1490, el

${ }^{8}$ AHPC, PN, 18-3a(04), fol. 1003 r., 1490, octubre, 8. 
bachiller Juan Díaz de Torreblanca atendió de esa enfermedad a una mujer llamada Isabel Ortiz ${ }^{9}$ Y el acta notarial describe que en el proceso de las correspondientes curas "le sacó (sic) los huesos de las manos e de los pies e le aserró muchas postillas costrosas con llagas y de muchas inflaçiones e alacraçiones" ${ }^{10}$. Todo lo cual demuestra que, lejos de ser abandonados a su suerte, los leprosos o, al menos, algunos de ellos, recibían cuidados médicos a pesar de que se era consciente de que "syempre la enfermedad non çesaua de seguir sus términos" ${ }^{\prime 1}$. Otro testimonio unos pocos meses anterior nos presenta al bachiller Fernández de Medina estableciendo un contrato para curar de la misma enfermedad a Mendo de Sahagún, vecino de la ciudad de Ecija $^{12}$. Dado el carácter casi siempre incurable de la lepra, resulta sorprendente leer en ese documento que el citado bachiller, miembro de una ilustre familia de médicos, se comprometiera, "sy no sanare e dyere sano al dicho Mendo de la dicha lepra, de dar e boluer... todos los mrs. que obyere resçebido" ${ }^{13}$.

Son frecuentes las alusiones a la naturaleza contagiosa de la enfermedad, a la que se define como "incurable..., que se pega"14. De ahí el que se procurara el aislamiento de los enfermos, a fin de evitar la extensión de una dolencia tan temida. De ello velaban los alcaldes de físicos y cirujanos, que lo eran también de enfermos de lepra. Una actuación concreta en este último cometido fue la que realizó el alcalde Alfonso Ruiz, en $1483^{15}$. Tuvo como objeto enviar a la casa de S. Lázaro, cerca de la muralla de Córdoba, a un leproso llamado Francisco de Castro, vecino de la collación de S. Andrés. La falta de medios económicos de los padres del leproso unida al peligro de contagio de sus cinco hermanos restantes aconsejaban la reclusión, que fue decretada por el citado alcalde.

Otra enfermedad característica de la época es la peste. El concejo de Córdoba adopta medidas drásticas, a veces, para evitar la entrada de ese tipo de epidemias en la ciudad. 'Así, en 1495, el cabildo municipal, conociendo

\footnotetext{
${ }^{9}$ Ibídem. El documento dice que era la esposa de "maestro Pero", quizá alguno de los varios médicos y cirujanos de ese nombre que había en Córdoba.

${ }^{10}$ Ibídem.

"Ibídem.

${ }^{12}$ AHPC, PN, 14-23(25), cuad. 5, fol. 30 v. 1490, junio, 26, Córdoba.

${ }^{13}$ Ibidem.

${ }^{14} \mathrm{~L}$. GRANJEL, La medicina española renacentista, p. 106.

${ }^{15}$ AHPC, PN, 14-18(20), cuad. 7, fol. 173 r., 1485, octubre, 19. Córdoba.
} 
que había pestilencia en Málaga, prohibió terminantemente la entrada a toda persona procedente de ella, aunque viniera a traer pescado ${ }^{16}$. No siempre puede identificarse como peste bubónica lo que los textos de la época llaman pestilençia. Uno de ellos, que data de 1473, habla de calentura pestilençial, que produjo a la enferma que la padeció grandes dolores del costado ${ }^{17}$. Otro, de 1487 , se refiere a un niño que, además de una llaga en la cabeza, padecía cabroche pestilençial y tenía una landre (buba) en la ingle del tamaño de una nuez ${ }^{18}$. Y era la buba inguinal y no la herida en la cabeza la que inquietaba al médico, que dio un pronóstico fatal. Una mención más tardía, de 1500, nos refiere la muerte de pestilencia de dos niños mudéjares, hermanos, y de una mujer, también mudéjar ${ }^{19}$. Anteriormente, con motivo de la conquista de Málaga, en 1487, tras la cual se produjo la cautividad de todos sus habitantes, muchos de ellos, traidos a Córdoba, murieron de distintas dolencias, de lo cual hay constancia documental en los protocolos cordobeses $^{20}$. En muchos casos se habla de pestilencia y, en efecto, la hubo a mediados de $1488^{21}$. En otros, como es habitual en la época, tenemos que renunciar a conocer la enfermedad que padecían para conformarnos solamente con los síntomas, entre los cuales están, por ejemplo, lo que en la época se llaman cámaras (diarreas) ${ }^{22}$ y çiçiones (calenturas) ${ }^{23}$, que podían estar presentes en muchas y muy variadas dolencias.

Junto a la lepra y a la peste, son frecuentes las alusiones a las enfermedades en el aparato genital. No nos referimos ahora a las citas documentales más bien rutinarias referentes a problemas circunstanciales como a la desfloración accidental, en las niñas, o a intervenciones quirúrgi-

${ }^{16} \mathrm{AMC}$, Actas Capitulares (AACC), reunión correspondiente al 27 de marzo de 1495.

${ }^{17}$ AHPC, PN, 14-11(08), Cuad.4-20, fol. 2 r., 1473, febrero, 14, Córdoba.

${ }^{18} \mathrm{AHPC}, 14-20(22)$, Cuad. 5, fol. 40 v., 1487, septiembre, 22, Córdoba.

${ }^{19} \mathrm{AHPC}, \mathrm{PN}, 14-34(36)$, Cuad. 14, fol. 1 r. 1500, mayo, 17, Córdoba.

${ }^{20}$ Sobre la conquista de Málaga, ver M.A. LADERO, Granada, historia de un país islámico, p. 147

${ }^{21}$ Docs. de 1488, junio, 6, AHPC, PN, 14-21(23), cuad. 7, fol. 15; 1488, junio, 13, AHPC, PN, 14-21(23), cuad. 7, fol. 35; 1488, julio, 7, AHPC, PN, 14-21(23), cuad. 4, fol. 6 y 9 y 1488, diciembre, 2, AHPC, PN, 14-21(23), cuad. 18, fol. $29 \mathrm{v}$.

${ }^{22}$ Ese es el síntoma que presentaba Mahamed Canchihed, uno de los moros que le fueron entregados al jurado Diego de Gahete, de los prisioneros de Málaga, el cual venía doliente de cámaras y falleció poco después. Ver AHPC, PN, 14-20(22), cuad. 3, fol. 9 v.-10, doc. de 1487, octubre, 5.

${ }^{23}$ De çiçiones murió otro moro malagueño, de 60 años, llamado Caçín. Ver AHPN, PN, 1802(03), fol. 17, doc. de 1489, enero, 9; ibidem, fol. 439 v., doc. de 1489, octubre, 16. 
cas de menor entidad, en los varones, que pudieran ser confundidas con la circuncisión y que son propias, en este último caso, del deseo de evitar toda identificación futura del paciente con el grupo de los judíos ${ }^{24}$. Al margen de ellas, algunos testimonios parecen apuntar hacia infecciones o enfermedades genitales de carácter más grave, que hacían necesaria una intervención quirúrgica cuyo riesgo era el que justificaba dejar constancia escrita sobre la actuación del cirujano. Sobre este tipo de enfermedades contamos con dos testimonios en los cuales se describe la dolencia recurriendo a la palabra cancre, cuya significación exacta no es fácil interpretar correctamente. El primero habla "de una llaga de cancre que diz que se le avíe fecho al dicho Pedro en su natura"25. El otro testimonio habla de un caso de idéntica localización que hizo necesaria la intervención del físico y cirujano maestro Lope porque, de no haberlo hecho, "peligrara e se comiera (sic) de

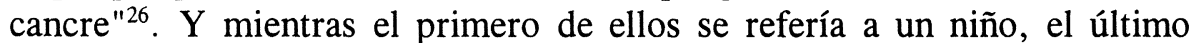
afectaba a una persona adulta y da que pensar sobre si se trataría o no de una enfermedad de transmisión sexual. Con los datos que proporciona el documento es imposible saberlo, pero informaciones como ésa alimentan el debate sobre una de las cuestiones más candentes de la historia de la Medicina: la existencia o no de la sífilis con anterioridad a $1492^{27}$. La sífilis, llamada también mal de bubas, sarna egipcíaca, morbo gálico y mal de Nápoles, debió de tener una gran incidencia en Córdoba, pues nos consta

\footnotetext{
${ }^{24}$ Un testimonio relacionado con esa forma de pensar lo tenemos en un documento al que le falta la fecha del año, si bien es, con toda probabilidad, de 1490, en el que Diego de Palma quería dejar constancia de que un hijo suyo, nacido el 16 de julio del año en cuestión, había nacido circuncidado (AHPC, PN, 18-02(03)3, fol. 301, 1490? [s.a.], julio, 18. Córdoba). Un caso de desfloración accidental, en AHPC, 14-13, 23, 2 r., doc de 1477, marzo, 7.

${ }^{25}$ AHPC, PN, 14-01(01), Cuad. 4, fol. 42 v., 1460, junio, 2, Córdoba.

${ }^{26}$ AHPC, PN, 14-10(13), cuad. 10, fol. 13 r., 1477, octubre, 29, Córdoba.

${ }^{27}$ Sobre ese debate, ver: A. LAPUENTE MATEOS, Sífilis en Europa antes de 1492 y Pedro Mártir de Anglería. Su personalidad y su testimonio. "Medicina", XVIII (Madrid, 1949), 2, pp. 115-128 y 6, pp. 441-458. Del mismo autor: Pedro Mártir de Anglería y la sífilis precolombina. "Medicamenta", XVI-206 (Madrid, 1951), pp. 215-217. Ver también: J. RIQUELME SALAZAR, Martín Alonso Pinzón. Rasgos de su enfermedad. Una teoría americana sobre el origen de la sifilis. Madrid, 1947. Del mismo autor: El descubrimiento de América y su repercusión en la sanidad de los habitantes de Europa, "Archivo Iberoamericano de Historia de la Medicina y de Antropología médica", VIII (Madrid, 1956), pp. 339-341. Un libro reciente sobre el tema es el de J. ARrizabalaga y R. French, The French Disease in Renaissance Europe, Yale University Press, New Haven and London, 1997.
} 
la existencia de un hospital dedicado a ella, cuya fundación promovió allí, en 1540, el gremio de los fabricantes de paños ${ }^{28}$.

Junto a esas enfermedades de carácter grave encontramos referencias a otras dolencias de menor entidad. Son muy frecuentes las alusiones a los procesos ulcerosos, más frecuentes entonces de lo que nos parece normal en nuestra época y que son, probablemente, una consecuencia de la falta de higiene. Cardoner ha relacionado esta última con la abundancia de enfermedades en la piel durante la Edad Media ${ }^{29}$. En Murcia aparecen citados expresamente los "maestros de las llagas", nombre que pone de manifiesto una especialización cuya existencia estaba justificada por una necesidad más o menos generalizada ${ }^{30}$. Los contemporáneos usaban los términos apostema, úlcera y llaga para describir situaciones muy diversas ${ }^{31}$. Entre las llagas distinguían dos clases: las llagas viejas o úlceras y las llagas nuevas, que equivalían a las heridas ${ }^{32}$. La curación de llagas y úlceras constituye uno de los cometidos más habituales de los cirujanos y aparecen contínuamente aludidas en la documentación. En 1460 encontramos una intervención para curar de una llaga genital a un niño pequeño ${ }^{33}$. Otro testimonio nos habla de unas llagas y frochasón que padecía un aprendiz de zapatero ${ }^{34}$. El bachiller Torreblanca atendió, en 1487 a un niño que, además de padecer síntomas de pestilencia, tenía una llaga en la cabeza ${ }^{35}$. Y de 1490 data un acuerdo suscrito con un cirujano de Sevilla por Alfonso de Priego, sedero, para que le curara de unas úlceras en las piernas ${ }^{36}$.

${ }^{28}$ L. GRANJEL, La medicina española renacentista, pp. 108 y 209-212. Sobre este tema, ver también: A. CARDONER I PlanAS, Història de la Medicina a la Corona d'Aragó, cit., p. 163.

${ }^{29}$ A. CARdoner I Planas, Història de la Medicina a la Corona d'Aragó, p. 150.

${ }^{30}$ J. TORRES FONTES, op. cit., p. 211.

${ }^{31}$ L. GRANJEL, La medicina española renacentista, p. 224.

${ }^{32}$ Ibídem, p. 21.

${ }^{33}$ AHPC, PN, 14-01(01), Cuad. 4, fol. 42 v.

${ }^{34} \mathrm{AHPC}$, PN, 14-07(07), cuad. 5, fol. 41 v., 1471, noviembre, 11, Córdoba.

${ }^{35} \mathrm{El}$ documento dice que los médicos "le miraron una llaga que tenía en la cabeça e que ya estaua sana la dicha llaga, e que le tomaron el pulso e que avían fallado en él una gran calentura contina, e que le miraron los braços e los pechos e que lo vieron lleno de cabroche pestilençial e que lo miraron abaxo en la pierna e que le fallaron en la yngle una landre casi tan gorda como una nues, e asy visto, que pronosticaron luego morir el dicho (en blanco) de la dicha landre e no de la dicha ferida de la dicha cabeça e que esto es asy verdad según dicho avían so cargo del dicho juramento que avían fecho..." [AHPC, 14-20(22), Cuad. 5, fol. 40 v, 1487, septiembre, 22, Córdoba].

${ }^{36} \mathrm{AHPC}, \mathrm{PN}, 18-3 \mathrm{a}(04)$, fol. 1111 
Los contemporáneos no siempre tenían suficientes conocimientos para diferenciar con claridad las manifestaciones patológicas a las que se refieren en sus libros con los nombres de úlceras, flemones, apostemas y tumores, a pesar de las explicaciones más o menos complejas que algunas veces dan de ellos en los tratados de medicina o de cirujía. Tanto unas como otros podían ser de muy diversa naturaleza y no todos tenían el mismo pronóstico. Con frecuencia encontramos alusiones a algunos de ellos que los contemporáneos juzgaban como malignos o incurables. Así sucede con el zaratán o cáncer de mama, que suele estar bien representado en la documentación. Más adelante se aludirá de forma detallada a esa cuestión al hablar del maestro de zaratanes, Antón García de Orabuena. Varios documentos referentes a la actuación de este curandero nos describen algunos elementos del cuadro clínico, junto con la actitud de los contemporáneos ante una enfermedad como ésa, que era especialmente temida.

Pero los médicos de la época, sin conocer exactamente su origen, sabían diferenciar, en la práctica, las dolencias de pronóstico fatal de aquellas otras que, pese a la apariencia más o menos aparatosa de sus síntomas, no ofrecían mayores problemas para conseguir la curación. Ciertos testimonios de la época lo ponen de manifiesto. Sólo así es posible explicarse algunos de los acuerdos que establecían para conseguir la curación de sus enfermos. Uno de ellos, recogido por Torres Fontes, se refiere a un çaratán urçerado, que padecía una vecina de Murcia y del cual fue curada por un cirujano de Orihuela, que se comprometió, incluso, a garantizar que no se reproduciría en el plazo de un año. El cirujano acertó en el pronóstico, aunque nos queda la duda de si verdaderamente se trataba de una dolencia más benigna que, por su ubicación, fue conceptuada por otros cirujanos consultados como más grave de lo que verdaderamente $\mathrm{era}^{37}$.

En Córdoba es también frecuente esa clase de testimonios en los que un médico o cirujano, un curandero o un boticario dejan constancia escrita de un acuerdo para la curación de una enfermedad, asignando plazo para conseguirla y estipulando un precio y unas condiciones. Todo ello implica un alto grado de confianza en la capacidad de esos profesionales tanto por parte de ellos, en sí mismos, como por parte de los enfermos que se ponían

\footnotetext{
${ }^{37} \mathrm{~J}$. TORRES FONTES, Los médicos murcianos en el siglo XV, pp. 253 y 265-266.
} 
en sus manos. Torres Fontes ha recordado que el Fuero Real estipulaba algunas disposiciones en relación con ese tipo de acuerdos ${ }^{38}$.

Algunos de los procedimientos habituales de la medicina de entonces pueden causarnos una sonrisa pero formaban parte de las prácticas médicas más extendidas. Entre ellas, la de la sangría se ha estado utilizando ininterrumpidamente hasta mediados del pasado siglo. Respondía a las teorías entonces imperantes sobre el origen de las enfermedades infecciosas, en una época muy anterior a los grandes descubrimientos de Pasteur. La sangría no dejaba de tener, a veces, ciertos efectos beneficiosos, si no en el remedio de las dolencias, sí, en cambio, en el estado aparente de los enfermos, sobre todo en los enfermos febriles, quienes, después de habérseles practicado, llegaban, obviamente, a un estado de sedación que se tenía por beneficioso, aunque muchas veces era la antesala de un colapso irremediable ${ }^{39}$. La práctica de las sangrías estaba encomendada generalmente a los barberos, que en un documento de cordobés de 1498 se titulan pomposamente a sí mismos flebotomianos, es decir, sangradores, y aparecen en una lista que incluye más de veinte ${ }^{40}$.

Hay numerosos testimonios sobre la práctica de la sangría en relación con las más variadas dolencias. Es lo primero que manda hacer uno de los numerosos médicos de la época, maestro Juan, el hijo de maestro Lope, cuando le presentan el caso de una sirvienta aquejada de pestilencia, a la que mandó "sangrar e purgar e faser todas las otras diligençias quantas fueron menester a su enfermedat"4l. Lo mismo sucede con un trabajador de Ecija, que padecía dolor de costado ${ }^{42}$. Y es idéntico procedimiento el empleado,

\footnotetext{
${ }^{38}$ En él se especifica que "Si algún físico o maestro de llagas tomare a alguno en guarda por pleyto que lo sane, e si ante que sea sano de aquella enfermedad muriere, no pueda demandar el precio que habíe taxado; e esto mesmo sea si puso sanarlo a plazo señalado, e no lo sanó". J. TORRES FONTES, op. cit., p. $254 n^{\circ} 1$

${ }^{39} \mathrm{Granjel}$ cita el testimonio de un noble alemán de finales del siglo XVI, el barón de Bemelberg, que estuvo en España en 1599, el cual compadecía "a qualquier hombre honrado de las enfermedades de España y de sus médicos, querría decir asnos, pues la primera medicina que harán es sangrar a una persona, y sacarla tanta sangre del brazo como si no fuera hombre, sino buey y otro animal grueso". L. GRANJEL, La medicina española renacentista, p. 253.

${ }^{40}$ En Córdoba, los contemporáneos dicen siempre, por transposición, "flemotobianos" AHPC, 14-34, cuad. 7, fol. 19r, doc. de 1498, marzo, 13, Córdoba. Publicado en E. CABRERA, R. CóRdoBA, J.L. DEL PINO, Córdoba Medieval, en "Textos histórico-geográficos de Córdoba y su provincia", Córdoba, 1988, pp. 317-318.

${ }^{41}$ AHPC, PN, 14-11(08), Cuad.4-2 ${ }^{\circ}$, fol. 2 r., 1473, febrero, 14, Córdoba.

${ }^{42}$ Doc. de 1489, junio, 30, Córdoba. AHPC, PN, 18-3, fol. 270 r.
} 
casi como primera medida, con un presunto herido de la guerra de Granada, en $1490^{43}$.

La purga es otro recurso habitual, pero mucho menos documentado ${ }^{44}$. $\mathrm{Y}$, previamente a toda otra diligencia, el médico habrá procedido a tomar el pulso al paciente, con el fin de determinar si tiene o no calentura ${ }^{45}$. Nos horroriza pensar en ciertas intervenciones quirúrgicas que se describen en algunos de esos documentos. Y es fácil de imaginar el dolor que podían producir esas intervenciones, que se desarrollaban sin el paliativo de medios anestésicos adecuados.

\section{LA FORMACIÓN DE LOS MÉDICOS}

Como en otros lugares del reino de Castilla, quienes en la ciudad de Córdoba se dedicaban profesionalmente al ejercicio de la medicina en alguna de sus formas o facetas solían estar comprendidos en varias categorías o grupos profesionales que en muchos casos no resulta fácil delimitar con precisión. $\mathrm{Al}$ frente del sector estaban aquellos que aparecen en los documentos con el nombre de físicos, los cuales suelen ser denominados con ese apelativo y también con el de cirujanos, estando unidas muchas veces ambas denominaciones en la misma persona. Pero junto a ellos encontramos también a otros "prácticos" en el arte de curar que, sin estudios superiores en la mayoría de los casos, ejercían ciertos cometidos en el campo sanitario, a veces sumamente especializados. Así sucede, entre otros muchos, con los llamados algebristas, especializados en las roturas o dislocaciones de huesos, y también con los dedicados al tratamiento de hernias, sin olvidar a las parteras y a los barberos, estos últimos dedicados, entre otras actividades, al doble cometido de realizar las sangrías y las extracciones dentarias.

Quienes practicaban la medicina a un nivel superior solían ostentar con frecuencia el título de bachiller, más raramente el de licenciado y también, en algún caso, el de doctor, todos los cuales denotan una formación universitaria más o menos completa. Pero al igual que sucedía en otros lugares, la mayoría de los que aparecen citados en los documentos del siglo

\footnotetext{
${ }^{43} 1490$, octubre, 5. Córdoba. AHPC, PN, 18-4, fol. 996 r.

${ }^{44}$ AHPC, PN, 14-11(08), Cuad. 4-2 ${ }^{\circ}$, fol. 2 r., 1473, febrero, 14, Córdoba.

${ }^{45}$ Un ejemplo sobre el particular, en AHPC, 14-22, Cuad. 5, fol. $40 \mathrm{v}$.
} 
XV suelen recibir con más frecuencia el apelativo de "maestros". Tal expresión se usa casi siempre unida al nombre de pila del médico, sin mencionar nunca o casi nunca su apellido. En teoría sería equivalente - salvando las diferencias - a la costumbre practicada en nuestros días de denominar a los médicos con la palabra doctor, seguida de su apellido y sin usar el nombre. Es difícil deslindar con claridad, a partir de esas denominaciones, la cualificación profesional de las personas que las ostentaban. No ofrece duda, en principio - salvo algún caso aislado que en su momento señalaremos-, la formación universitaria de quienes hacían uso de los títulos citados en primer lugar; pero puede haberlas en relación con quienes son denominados "maestros". García Ballester ha subrayado la doble vía existente en la Edad Media para la formación de los médicos: por una parte, la que implicaba los estudios universitarios más o menos largos y completos y, por otra, la que discurría en el ámbito de lo privado a través de un proceso de aprendizaje conseguido junto a un médico en ejercicio ${ }^{46}$. Podría pensarse que los "maestros" son aquellos que adquirían el dominio de sus habilidades médicas de forma particular, bien por tradición familiar - que tanta importancia tiene desde siempre en el campo de la Medicina- bien a través del contacto directo con una persona debidamente cualificada que les enseña el oficio. En efecto, la expresión "maestro" se suele utilizar también en la época para referirse a aquellos miembros del sector artesanal que habían conseguido el más alto grado de especialización en la práctica de cualquiera de los oficios manuales característicos de aquella época. Pero, según creemos, esa denominación nada tiene que ver con la condición de "magister" adquirida en el mundo universitario y alcanzada por quienes obtenían un nivel superior al de bachiller y licenciado. Por el contrario, la cualificación profesional de maestro quedaba definitivamente consagrada a partir de las pruebas o exámenes, realizadas a nivel local, en las cuales el candidato demostraba de forma fehaciente los conocimientos teóricos y prácticos del oficio al más alto nivel. Es ésta, en definitiva, la cualificación profesional característica de lo que algunos documentos llaman el "maestro esaminado", es decir, aquel que ha demostrado sus conocimientos ante un tribunal de los de su mismo oficio diputados para ello.

\footnotetext{
${ }^{46}$ L. García Ballester, La Medicina, en "Historia de España" dirigida por D. Ramón Menéndez Pidal, XVI, p. 618.
} 
Por otra parte estaban quienes habían estudiado en la Universidad ${ }^{47}$. Los que habían salido de sus aulas solían hacer constar tan sólo sus títulos de bachilleres, licenciados o doctores. Pero una y otra situación pueden darse $\mathrm{y}$, de hecho, se dan con cierta frecuencia en una misma persona. Por ejemplo, en los años setenta, Maestro Gonzalo suele ser designado así, especificando, al mismo tiempo, que es bachiller ${ }^{48}$, aunque lo más normal en los titulados universitarios sea el hecho de no usar la denominación de maestro. Así sucede, por ejemplo con Gonzalo de Córdoba, quien antepone a su nombre el título de bachiller o lo hace seguir del título "bachiller en Medicina"49. Lo mismo sucede con su padre, el doctor Juan Martínez de Córdoba $^{50}$. Por otra parte, parece evidente un desuso paulatino del título de "maestro" entre los médicos a partir de la década de 1480 fecha en torno a la cual empiezan a ser nombrados cada vez con más frecuencia mediante la utilización de su nombre completo y sin aquel apelativo. Ello puede ser un indicio de un cada vez más frecuente acceso de los médicos a la Universidad pues ese paulatino abandono de la expresión "maestro" parece coincidir con la creciente mención de títulos universitarios entre los profesionales de la medicina. Es decir, que al mismo tiempo que decrece el número de médicos denominados "maestros" aumenta el de los que son llamados "bachilleres" o "bachilleres en medicina". Incluso parece evidente, según se ha visto, que, salvo excepciones, quien usa el apelativo de maestro no se titula bachiller, y a la inversa. $Y$ en algunas de esas excepciones a la regla hay motivos para dudar si el título de bachiller usado es legítimo o no. Tal diferenciación permite conjeturar que los llamados maestros no tienen, también salvo excepciones, título universitario. Ello quiere decir que la formación médica $o$, al menos, la formación de los cirujanos, que antes de ese punto de inflexión se conseguía muchas veces a través de contratos privados de aprendizaje con alguno de los cirujanos en ejercicio, se solía complementar cada vez más en las aulas y con un título académico que respaldase los

\footnotetext{
${ }^{47}$ Sobre el tema, véase: L. GARCÍA BALLESTER, Universidad y nueva profesión médica en la Europa latina medieval, en S. AGUADÉ (coord.), "Universidad, cultura y sociedad en la Edad Media", Alcalá de Henares, 1994, pp. 105-129.

${ }^{48}$ AHPC, PN, 14-09(12), doc. de 1476, mayo, 5.

${ }^{49} \mathrm{AGS}, R G S$, fol. 63 , doc. de 1478 , mayo, 26. Lo mismo sucede en el caso del "bachiller en Medicina" Antonio de Córdoba (AHPC, PN, 14-22, fol. 66 v., 1489, noviembre, 26).

${ }^{50}$ Ibídem, fol. 18, doc. de 1478, mayo, 26. Al menos eso es lo que parece deducirse de la documentación más tardía, porque resulta difícil saber si este personaje es alguno de los que aparecen denominados anteriormente con el apelativo de "maestro Juan".
} 
conocimientos médicos. Seguramente el proceso que se seguía cada vez con mayor intensidad en los estudios de Medicina se iniciaba aprendiendo los rudimentos del oficio en contacto con un maestro físico o cirujano - que muchas veces era el padre del médico en ciernes-, tras lo cual se completaba la formación adquirida con algunos cursos en la Universidad. Pero todo ello no es más que una hipótesis, difícil de demostrar en la práctica a causa de la escasez y, sobre todo, de la falta de idoneidad de las fuentes de las que podemos disponer.

De todas formas, es importante subrayar que el título universitario no es el único indicador que determina la valía o el reconocimiento social de un profesional de la medicina. Y así, por ejemplo, encontramos algunos médicos que, usando el apelativo de "maestro" y sin que la documentación haga alusión alguna a sus títulos universitarios, tuvieron a su cargo, sin embargo, el cuidado de la familia real, como sucede en el caso del físico y cirujano "maestro" Andrés de Paredes ${ }^{51}$.

Respecto de los médicos que poseían estudios universitarios y ejercían en la ciudad de Córdoba, carecemos totalmente de referencias que nos permitan conocer en qué universidad estudiaron. Ni siquiera sabemos, en muchos casos, si eran originarios de la propia ciudad o llegaron a ella procedentes de distintos lugares de la Península, como sucedía en otras ciudades del reino. El profesor J. Torres Fontes, que ha estudiado minuciosamente la historia de los médicos de Murcia, ha comprobado que en no pocas ocasiones acudieron a esa ciudad procedentes de Orihuela. Sobre ellos se tiene una información más detallada ${ }^{52}$. En Córdoba no sucede así. En ciertos casos parece deducirse que algunos médicos de los que ejercían en la ciudad procedían de otros lugares - como sucede con el bachiller Cabeza de Vaca, que era de Sevilla - o bien formaban parte de ilustres familias de médicos que tenían dispersos a otros de sus miembros por diferentes ciudades del reino, como en el caso del licenciado Juan Rodríguez de Santa Cruz. Sin embargo, en la mayoría de las ocasiones cabe pensar que estamos ante personas que, con toda probabilidad, han nacido en Córdoba y desde

\footnotetext{
${ }^{51}$ Con el título de físico y cirujano de los reyes aparece este médico, que era vecino de Madrid. Ver AHPC, PN, 14-17(19), fol. 144 r., doc. de 1484, julio, 13.

${ }^{52} \mathrm{Ver}$ J. TORRES FONTES, Los médicos murcianos en el siglo XV, "Miscelanea Medieval Murciana", 1 (1973), pp. 203-267 y De Historia médica murciana. I: Los médicos. Murcia 1980.
} 
ella marcharon a obtener su formación a aquellos lugares donde más fácil y eficazmente podían conseguirla.

Los títulos que la documentación atribuye a los médicos cordobeses nos pueden ayudar a conocer su grado de formación académica. Una buena parte de ellos aparecen usando el título de bachiller. Como ya se ha indicado, son cada vez más frecuentes a finales de siglo. Sin ánimo de llegar a la exhaustividad citaremos algunos casos. Por ejemplo, Juan Díaz de Torreblanca ostentaba ese título ${ }^{53}$. Se otorga también a sí mismo el título de bachiller el maestro Ferrand de Oliva o Ferrand Pérez de Oliva. Pero, en ambos ejemplos, su condición de alcaldes de físicos y cirujanos hacía más necesarios los estudios superiores ${ }^{54}$. Uno y otro son dos personajes del máximo interés. El primero fue bisabuelo de Miguel de Cervantes y amigo íntimo de Colón durante la estancia de éste en Córdoba ${ }^{55}$. El segundo fue el padre del célebre humanista del mismo nombre. Con anterioridad a ellos, en 1473, encontramos al bachiller maestro Juan, el hijo de maestro Lope ${ }^{56}$. Tenemos también al bachiller maestro Juan, físico y cirujano, hijo de Ferrand Alfonso ${ }^{57}$. En 1490 está igualmente documentado otro bachiller, que es cirujano: Antón Martínez de Molina ${ }^{58}$. Otro médico que ostenta el título de bachiller es Alfonso Fernández de Medina, hijo del doctor de Medina $^{59}$. Este último, ya difunto en 1490 , es uno de los pocos doctores que hemos encontrado en Córdoba, junto con el también doctor Juan

\footnotetext{
${ }^{53}$ Así se le denomina en doc. de 1487, septiembre, 22, AHPC, 14-20(22), cuad. 5, fol. 40 v.; en 1489, noviembre, 27, AHPC, PN, 18-02(03), fol. 507 v.; en 1490, marzo, 18, AHPC, PN, 18-03(05), fol. 690 v. y también en 1490, octubre, 8, AHPC, PN, 18-3a(04), fol. 1003 r. En ese mismo documento encontramos, junto a Torreblanca, otro físico y cirujano que se titula también bachiller: maestre Alfonso.

${ }^{54} 1490$, abril, 20. Córdoba. AHPC, PN, 18-3a(04), fol. 754 r. Sin embargo, su colega, maestro Pedro, no aparece con el título. Nuevamente el bachiller Oliva en 1496, julio, 18, Córdoba (AMC, AACC, 4, XIX, 2).

${ }^{55}$ Ver sobre este personaje, M. CABRERA SÁnchEZ, Un médico olvidado de la Córdoba del siglo XV: el bachiller Juan Díaz de Torreblanca, "Historia, Instituciones, Documentos", 23 (1996), pp. 99-113.

${ }^{56} \mathrm{AHPC}, \mathrm{PN}, 14-11(08)$, cuad. $4,2^{\circ}$, fol. $2 \mathrm{r}$

${ }^{57}$ Doc. de 1489, octubre, 20. Córdoba, AHPC, PN, 18-02(03), fol. 446.

${ }^{58}$ Doc. de 1490 , noviembre, 7 , AHPN, PN, 18-03(05), fol. 120. También en 1494, enero, 31 (AHPN, PN, 18-03(05), fol. 503 v).

${ }^{59}$ Doc. de 1490, junio, 26, AHPC, 14-23(25), cuad. 5, fol. 30v. También en doc. de 1491 noviembre, 27, AHPC, PN 14-26 y doc. de 1494, enero, 13, AHPN, PN, 18-03(05), fol. 441v.
} 
Martínez de Córdoba, ya citado, que fue médico de Enrique $\mathrm{IV}^{60}$, sin olvidar a Juan Sánchez, el más antiguo de todos los médicos cordobeses de nombre conocido en el siglo $\mathrm{XV}^{61}$. Está documentado también en Córdoba - aunque con toda probabilidad no era natural de ella - el doctor Juan de Ribasaltas, médico de los reyes y alcalde examinador del reino ${ }^{62}$. Licenciados sólo hemos encontrado uno, Juan Rodríguez de Santa Cruz, miembro de una ilustre familia de galenos, de origen converso, que ejerció el cargo de alcalde de físicos y cirujanos y era veinticuatro de Córdoba ${ }^{63}$.

Lo normal es que los títulos de bachiller, licenciado o doctor aparezcan aplicados a una persona concreta, sin ninguna referencia más a la materia en la que eran especialistas. Por ejemplo: el bachiller Juan Díaz de Torreblanca. Pero alguna vez a ciertos personajes se les cita como bachilleres en Medicina. Son casos raros. Entre los llamados así con ese título concreto está Gonzalo Sánchez, que aparece documentado en $1474^{64}$. También aparece con esa titulación maestro Juan, el hijo de maestro Lope ${ }^{65}$.

Sucede a veces que, ante algunos testimonios, cabe preguntarse si los médicos o cirujanos de entonces tenían la costumbre de usar el título de "bachiller", sin serlo realmente, lo mismo que sucede ahora con muchos de ellos que se titulan doctores sin haber realizado la tesis doctoral. Parece que

\footnotetext{
${ }^{60}$ AGS, RGS, fols. 18 y 63, doc. de 1478, mayo, 26. Juan Martínez es, sin duda, el mismo que aparece mencionado en un documento de 1465 como "el dotor jurado de Sant Saluador" [AHPC, PN, 14-03(03), cuad. 1, fol. 84 r. y v.]. Sabemos, en efecto, que Juan Martínez de Córdoba era jurado de San Salvador al menos en 1471 [AHPC, PN, 14-07(07), fol. 2r, doc. de 1471, febrero, 5]. Se trata del mismo personaje que aparece en otros documentos con el nombre de Juan Martínez de Santa Cruz y que ostentaba también el título de doctor [AHPC, PN, 18-01(02), fol. 257v, doc. de 1483, agosto, 18].

${ }^{61}$ Archivo de la Catedral de Córdoba, Obras Pías, leg. 616, doc. de 1442, enero, 15, Córdoba.

${ }^{62}$ En 1483 lo encontramos actuando en Córdoba en su condición de alcalde examinador tratando de impedir el ejercicio de la medicina a una mujer judía vecina de Carrión de los Condes. Ver AHPC, PN, 18-01(02), fol. 252 v., doc. de 12 de agosto de 1483.

${ }^{63}$ Doc. de 1470 , enero, 11, AHPC, PN, 14-06(06), cuad. 1, fol. 10 v. No sabemos si se trata del mismo personaje que, con el nombre de Juan Rodríguez, figura como físico del conde de Plasencia en Sevilla, en 1465 [AHPC, PN, 14-03(03), cuad. 1, fol. 111 r.]. Es dudoso que así fuera, porque este estimonio se refiere a él llamándole "doctor". y no "licenciado", aunque es ésta una confusión muy probable. También resulta difícil la indentificación con la persona que, respondiendo a idéntico nombre -Juan Rodríguez de Santa Cruz- aparece recusado, en 1478 , como alcalde mayor de físicos y cirujanos de Sevilla (AGS, RGS, fol. 90, doc de 1478, noviembre, 9, Córdoba).

${ }^{64}$ Doc. de 1474, mayo, s.d., AHPC, PN, 14-06(06), cuad. 5, fol. 37 r.

${ }^{65}$ Así lo llama Juana Rodríguez, viuda de maestre Lope, en un documento de 1468 , enero, 26, Córdoba, AHPC, PN, 14-03(03), cuad. 2, fol. 35 v.
} 
ocurre así en algunos casos. De 1477 data una mención del "bachiller, maestro Enrique, físico del arte de los quebrados", siendo lo más probable que se tratara, simplemente, de un empírico, tal como se referirá más adelante $^{66}$. Repitamos una vez más que es difícil en ocasiones, con los datos disponibles, establecer una separación entre aquellos que habían cursado estudios universitarios y quienes tal vez no poseían otra cosa que una formación práctica. C. Guilleré, refiriéndose a los médicos gerundenses del siglo XIV subraya que, habitualmente, los salidos de las universidades solían recibir los títulos de magister in medicina y también el apelativo de medicus, y puntualiza que la indicación de cirurgià, en catalán, acampañada de la de fisic, es el indicio que distingue al personal mejor formado ${ }^{67}$. Lo mismo puede decirse en Córdoba, donde los profesionales más cualificados suelen utilizar siempre los títulos unidos de "físico y cirujano".

Como ya se ha subrayado, al margen de la formación universitaria, ciertos cometidos de la Medicina podían ser aprendidos a título privado. Ese es el caso del oficio de cirujano, cuya enseñanza se realizaba de acuerdo con unos principios más o menos idénticos a aquellos que regían en el aprendizaje de cualquier otro de los muchos que se practicaban en la ciudad. En ese sentido, encontramos contratos de aprendizaje concebidos en los términos que son tradicionales en otros campos y de los cuales es fácil deducir que el nivel de conocimientos adquiridos era más bien modesto y que estos últimos tenían, sobre todo, una finalidad eminentemente práctica, como la de cualquier artesano dedicado a otro menester. Incluso es frecuente que en dichos contratos el maestro cirujano se comprometa a enseñar a su pupilo a leer y a escribir, como parte de la formación teórica que acompañaba a la enseñanza de su profesión ${ }^{68}$. Ello prueba que muchos de cuantos ejercían actividades médicas no sólo estaban carentes de una formación universitaria, sino que poseían un nivel cultural más bien precario, aunque sólo podían ejercer la profesión a partir del momento en que demostraban suficiente pericia en la práctica del oficio, tras haber superado las pruebas a las que les

\footnotetext{
${ }^{66} \mathrm{AHPN}, \mathrm{PN}, 14-10(13)$, cuad. 14, fol. 28.

${ }^{67} \mathrm{C}$. GUILlERÉ, Le milieu médical Géronais au XIV' siècle, p. 264.

${ }^{68}$ Dice así: "En Córdoua, en este dicho día siete días de noviembre del dicho año [1490] otorgó Diego de la Torre, fijo de Juan de la Torre, que Dios aya, que entra con el bachiller Antón Martínes Molina, vesino a Santo Andrés, que está presente, para que le abese leer e escriuir rasonablemente e le abese el arte de la çirugya a todo su leal poder pudiéndolo él aprender desde oy fasta çinco años siguientes que vernán e que le dé en el dicho tienpo de comer e beuer e vestyr e calçar e vida rasonable..." [AHPC, PN, 18-03(05), fol. 120].
} 
sometían los llamados "alcaldes examinadores"69. Tales pruebas tenían una doble misión: por una parte, conseguir que las prácticas médicas - y también las farmacéuticas - respondieran a ciertas garantías; por otra, evitar, de paso, el intrusismo de los empíricos, que debían de ser muy numerosos. Sobre el primer caso, es elocuente la actuación del alcalde examinador maestro Rodrigo autorizando a Alfonso Fernández a practicar el oficio de algebrista $^{70}$, o facultando a Maestro Martín para que pudiera ejercer de cirujano $^{71}$. Respecto de la supervisión de las cuestiones farmacéuticas, es igualmente elocuente la actuación del Bachiller Ferrand Pérez de Oliva y de maestro Pedro, alcaldes de los físicos, cirujanos, boticarios, especieros y herbolarios interviniendo en un asunto relacionado con la elaboración de un curioso preparado farmacéutico de zumo de rosas ${ }^{72}$. En la misma línea está la intervención, en 1493, de Juan Díaz de Torreblanca y de Maestre Pedro de León, como alcaldes, respecto de unos aceites de bayas con el que estaban relacionados unos mercaderes genoveses ${ }^{73}$.

Pero el tema de los exámenes necesarios para obtener el título que permitiera el ejercicio de la profesión médica no es demasiado bien conocido en Córdoba, tal vez como consecuencia de la pérdida de la mayor parte de su documentación municipal referente al siglo XV. Podemos suponer que se realizaban siguiendo unos principios que son bien conocidos en relación con otras ciudades del reino. Tal es el caso, ya citado, de Murcia, estudiado por Torres Fontes. Los protocolos notariales nos han proporcionado a veces alguna información a través de los certificados que el alcalde de físicos, cirujanos, herbolarios y enfermos de lepra otorgaba a quienes habían sido autorizados, en función de sus conocimientos, a practicar algunos de los cometidos médicos que estaban bajo la competencia y supervisión de esos alcaldes. Pero las actuaciones de estos últimos no se conocen con suficiente detalle y, en todo caso, sólo tenemos constancia de ellas a partir de los años sesenta del siglo XV. Por supuesto, la existencia de esos alcaldes examinadores es muy anterior, pues está comprobada su implantación en Castilla en el reinado de Juan II, aunque se discute si se llevó a cabo en 1420, en 1422 o

\footnotetext{
${ }^{69} \mathrm{~L}$. GRANJEL, La medicina española renacentista, p. 63.

${ }^{70}$ AHPC, PN, 14-04(04), cuad. 8, fol. 27 r., 1467, marzo, 9, Córdoba.

${ }^{71}$ AHPC, PN, 14-03(03), Cuad. 2, fol. 139 v., 1468, junio, 7, Córdoba.

${ }^{72} \mathrm{AHPC}, \mathrm{PN}, 18-3 \mathrm{a}(04)$, fol. 754 r., 1490, abril, 20. Córdoba.

${ }^{73} \mathrm{AHPC}, \mathrm{PN}, 18-03(05)$, fol. $349 \mathrm{v}$.
} 
en $1432^{74}$. Dichos alcaldes ejercían sus funciones como delegados, en cada ciudad, del alcalde mayor que el rey nombraba con idéntica misión y para todo el reino. Desempeñaron este último cargo, ya desde la época de Juan II, Pedro de Avila y Diego Rodríguez ${ }^{75}$.

Ya se han citado, incidentalmente, los nombres de los médicos que ostentaron el cargo de alcaldes examinadores en Córdoba. El más antiguo de los conocidos es maestro Rodrigo, que está documentado, como alcalde de físicos y cirujanos, en 1467 y $1468^{76}$. En 1470 aparece al frente de esa alcaldía el licenciado Juan Rodríguez de Santa Cruz, que era en esa fecha veinticuatro de Córdoba $^{77}$. En esa fecha autorizaba a ejercer la citada alcaldía, en su nombre, a su sobrino, el físico y cirujano Lope Rodríguez de Santa Cruz. El nombre de uno y otro permiten vincularles a la familia de uno de los alcaldes mayores de físicos y cirujanos del reino: en concreto, el ya citado doctor Diego Rodríguez. Torres Fontes sugiere la idea de que fueron dos individuos, padre e hijo, los que, con este último nombre -Diego Rodríguez- ejercieron ese cargo en los sucesivos reinados de Juan II y Enrique IV $^{78}$. Y menciona también a otro hijo de Diego Rodríguez cuyo nombre, Gonzalo Rodríguez de Santa Cruz, nos daría la clave para identificar a esa familia con la del alcalde de físicos y cirujanos de Córdoba. La familia Santa Cruz debía de ser originaria de Córdoba o, al menos, en esta ciudad residieron algunos de sus miembros dedicados a la medicina. El licenciado Juan Rodríguez de Santa Cruz es tan sólo uno de ellos. En 1490

\footnotetext{
${ }^{74}$ De 1422 la hace datar L.S. GRANJEL, op. cit., p. 74. Torres Fontes, en cambio, ha defendido, con sólidas razones, la fecha de 1420. Ver, de este autor, Los médicos murcianos en el siglo XV, en "Miscelánea Medieval Murciana", 1 (1973), p. 217 y nota $\mathrm{n}^{\circ} 7$.

${ }^{75}$ Un trabajo ya clásico sobre el tema es el de V. GómEZ MONMASO, Los alcaldes examinadores mayores. Origen y competencia, en "BRAH", 180 (1983), pp. 551-560. Una aportación reciente al tema de los alcaldes examinadores y de los orígenes del protomedicato en J. Riera Palmero, El protomedicato en Castilla a finales del siglo XV, en "Actas del Congreso Internacional de Historia 'El tratado de Tordesillas y su época'". Madrid, 1995, I, pp. 595-610. Este último autor ha reeditado hace algunos años la obra de P. IBORRA, Historia del protomedicato en España (1477-1822), Valladolid, 1987.

${ }^{76} \mathrm{AHPC}, \mathrm{PN}, 14-04(04)$, cuad. 8, fol. $27 \mathrm{r}$ y 14-03(03), cuad. 2, fol. $139 \mathrm{v}$.

${ }^{77} \mathrm{AHPC}, \mathrm{PN}, 14-06(06)$, cuad. 1, fol. $10 \mathrm{v}$. Tal vez un hijo suyo del mismo nombre es el personaje que, con el título de bachiller, figura como jurado de la collación de Santo Domingo, cargo que le fue restituido en 1478 , por orden de los reyes, y del que había sido, al parecer, despojado durante los sucesos de 1473. Ver AGS, RGS 1478, enero, 13, fol. 31.

${ }^{78} \mathrm{~J}$. TORRES FONTES, op. cit., pp. 221 y 222 y nota $\mathrm{n}^{0} 4$ de esa página.
} 
vuelven a estar documentados otros miembros de su familia ${ }^{79}$, pero en el espacio de esos veinte años hay poca información sobre la persona o personas que ejercían el cargo de alcalde de físicos y cirujanos. Unicamente está documentado en el ejercicio de ese oficio el físico Alfonso Ruiz, en $1485^{80}$. También nos consta la presencia, en Córdoba, en 1483, del doctor y protomédico Juan de Ribasaltas, físico de los Reyes y alcalde mayor del reino, aunque su estancia en esta ciudad es circunstancial y obedece, sin duda, a la presencia en ella de los reyes como consecuencia de la campaña granadina $^{81}$. En 1490 ejercían el cargo de alcaldes en Córdoba y su obispado, el bachiller Pérez de Oliva y el maestro Pedro ${ }^{82}$. Tres años más tarde ocupaban el puesto Juan Díaz de Torreblanca y el boticario maestre Pedro de León, sin duda el mismo personaje citado anteriormente ${ }^{83}$.

\section{TRANSMISIÓN DE LOS SABERES MÉDICOS}

Como indicaremos en otro lugar, los alcaldes examinadores no sólo ejercían sus funciones supervisando la formación de médicos y cirujanos, sino que, además, les competía la vigilancia de otros aspectos de la vida sanitaria de la ciudad, principalmente la de productos farmacéuticos ${ }^{84}$. También tenían a su cargo dictaminar sobre los enfermos de lepra y, así mismo, les competía dar las oportunas órdenes de reclusión respecto de

\footnotetext{
${ }^{79}$ De 1490 es la carta de dote $(75.000$ mrs.) de Leonor Rodríguez, esposa de Diego, hijo de Lope Rodríguez de Santa Cruz [AHPC, PN, 18-3a(04), fol. 857 r.]. Lope Rodríguez de Santa Cruz es, presumiblemente, el ya citado, que ejerció la alcaldía en nombre de su tío, en 1470. De 1490 data también la venta de la renta de las carnicerías de la catedral, tal como las poseía entonces, hecha por el anteriormente citado Lope Rodríguez de Santa Cruz, "hijo del jurado Diego Rodríguez" [AHPC, PN, 18-3a(04), fol. 940 v.].

${ }^{80}$ AHPC, 14-18(20), cuad. 7, fol. 173 r., 1485, octubre, 19. Córdoba.

${ }^{81}$ Ver AHPC, PN, 18-01(02), fol. 252 v.

${ }^{82} \mathrm{AHPC}, \mathrm{PN}, 18-3 \mathrm{a}(04)$, fol. $754 \mathrm{r}$.

${ }^{83} \mathrm{AHPN}, \mathrm{PN}, 18-03(05)$, fol. 349 v. Sin embargo, varios años después, el bachiller Oliva seguía prestando su colaboración ocasionalmente a los alcaldes de físicos y cirujanos. Eso es lo que se deduce de las Actas capitulares de ese año, en el que las autoridades cordobesas nombraron al citado bachiller para que colaborara con los alcaldes de médicos y cirujanos en los exámenes que éstos realizaban para autorizar el ejercicio de la medicina (AMC, AACC , $4^{\circ}$, XIX, 2).

${ }^{84}$ En 1490, por ejemplo, Ruy Ferrández, mercader, declara ante los alcaldes de físicos, cirujanos y boticarios no haber tenido ninguna responsabilidad en la elaboración de cierto preparado farmacéutico que se hizo en su casa [AHPC, PN, 18-3a(04), fol. $754 \mathrm{r}$ y fol. $760 \mathrm{v}$.].
} 
aquellos en quienes se hubiera diagnosticado la enfermedad ${ }^{85}$. De ahí el nombre de "alcaldes de físicos, cirujanos, boticarios, especieros herbolarios y enfermos de lepra" con el que habitualmente aparecen en los documentos.

Pero cualquiera que fuese la formación, la cualificación o la especialidad del personal sanitario de la época, es perfectamente observable que los saberes médicos pasan, muy frecuentemente, de padres a hijos. En el caso de la medicina cordobesa del siglo XV ese hecho es muy evidente y tenemos numerosos ejemplos, algunos de los cuales han sido ya mencionados con anterioridad. Es fácilmente imaginable también la importancia que tuvo la conservación y transmisión de conocimientos médicos entre los miembros de la comunidad judía. A pesar de ello, no resulta muy ostensible la presencia de judíos entre los componentes del sector sanitario de Córdoba, tal como está comprobado en otros lugares. A decir verdad, en la documentación examinada hasta ahora tan sólo hemos conseguido encontrar un ejemplo: el del físico Rabí Çad, vecino de la collación de San Bartolomé e "hijo de don Symuel de Domas" quien, en 1485, vendía su casa, todo ello seguramente como paso previo al exilio ${ }^{86}$. En ese aspecto, el contraste con otras ciudades es muy notorio. En Murcia, por ejemplo, Torres Fontes encuentra gran cantidad de judíos entre los sanadores de la ciudad, hasta el punto de que los médicos de ese origen eran, al parecer, la mayoría. Incluso subraya hasta qué punto fue ineficaz la prohibición que pesó alguna vez sobre ellos de ejercer la medicina sobre pacientes cristianos, pues no resultaba fácil sustituirlos por médicos de este último origen ${ }^{87}$. Seguramente las repercusiones del.pogrom de 1391 fueron muy diferentes en una y otra ciudad y ello explica las divergencias en un tema como ése. En Murcia, los judíos no recibieron prácticamente ningún daño, puesto que fueron protegidos por el obispo ${ }^{88}$; en Córdoba, por el contrario, el llamado Robo de la Judería fue de consecuencias dramáticas $\mathrm{y}$, al contrario que en otros lugares, debió de

\footnotetext{
${ }^{85}$ AHPC, PN, 14-18(20), cuad. 7, fol. 173 r.

${ }^{86} \mathrm{La}$ vendió por $45.000 \mathrm{mrs}$. al trapero Pedro Fernández, hijo del jurado Martín Alfonso, ambos miembros de una célebre familia de conversos [AHPC, PN, 14-18(20), fol. 40 r., 1485, abril, 15].

${ }^{87}$ TORRES FONTES, pp. 236 y ss.

${ }^{88}$ Ibídem, p. 238.
} 
producir numerosas conversiones ${ }^{89}$. De ahí el que sea un hecho manifiesto la presencia de numerosos conversos en el ámbito de la Medicina. Se ha subrayado que para los médicos judíos la conversión al Cristianismo podía resultar especialmete provechosa en varios sentidos. En efecto, por una parte les permitía el acceso a la Universidad - vedada a los judíos- de la cual podían obtener unos conocimientos que servían de complemento a los que ya poseían derivados de la tradición médica de los de su grupo social ${ }^{90}$. Por otra parte, podían acceder libremente a la práctica de su profesión con enfermos cristianos, respecto de los cuales no siempre tuvieron plena libertad - al menos en teoría- para ejercer su arte los médicos judíos ${ }^{91}$. También fue un hecho muy frecuente que los conversos $-\mathrm{y}$ de forma particular los médicos- ocuparan el cargo de jurado y no es ése un caso privativo de Córdoba $^{92}$. Y es con toda probabilidad esta circunstancia la que denuncian algunas de las quejas que la población de Córdoba formulaba en relación con el poder acumulado por los conversos al acusarles de ocupar los puestos clave del gobierno de la ciudad, todo lo cual estuvo en el origen de la revuelta que se produjo contra ellos en $1473^{93}$. Aunque, en rigor, el cargo de jurado era electivo, no faltaban ocasiones en las que el rey o, simplemente, la oligarquía gobernante en Córdoba favorecía la promoción de los

\footnotetext{
${ }^{89}$ "No ha quedado en ella grande ni chico que no apostatara de su religión" es el testimonio que nos transmite un poeta judío de la época. Y. BAER, Historia de los judios en la España cristiana, Madrid, 1981, II, p. 384.

${ }^{90} \mathrm{~J}$. TORRES FONTES, op. cit., pp. 235-236.

${ }^{91}$ De 1492 data una disposición de los reyes ordenando se cumpla una disposición dada en Cortes donde se prohíbe a los judíos y moros tener tiendas de pescado, aceite y viandas, ser especieros, boticarios y cirujanos y tener tiendas de boticas (AGS, RGS, 1492, febrero, 8, Córdoba, fol. 223).

${ }^{92}$ Es bien conocido el caso de los jurados-médicos de Gerona. Ver: C. GUILLERÉ, Le milieu médical Géronais au XIVè siècle, en "Santé, Médecine et assistance au Moyen Age. 110 Congrès National des Societés Savantes", Montpellier, 1985, I, París, 1987, p. 271.

${ }^{93}$ Sobre esas causas, ver la explicación dada por Diego de VALERA en Memorial de Diversas Hazañas, ed. Carriazo, Madrid, 1941, Cap. LXXXIII, p. 240. Contribuyen a aclarar el tema los trabajos siguientes: M. NIETO CUMPLIDO, La revuelta contra los conversos de Córdoba en 1473, "Homenaje a Antón de Montoro", Montoro, 1977, pp. 41-49; R. GRACIA BoIX, Colección de documentos para la historia de la Inquisición en Córdoba, Córdoba, 1982, y M. CABRERA SÁNCHEZ, El problema converso en Córdoba. El incidente de la Cruz del Rastro, en "Actas del Congreso Internacional: La Península Ibérica en la Era de los Descubrimientos, 1391-1492", celebrado en Sevilla del 25 al 30 de noviembre de 1991 (en prensa).
} 
conversos a ese puesto de la administración concejil ${ }^{94}$. En muchos casos la pertenencia al grupo de los conversos de algunos de los profesionales de la medicina cordobesa se vislumbra a través de ciertos indicios seguramente impalpables, pero que la intuición de toda persona estudiosa del tema suele detectar a menudo de forma casi infalible. Es uno de esos indicios la utilización de ciertos apellidos con nombre de ciudad y también aquellos que hacen alusión de manera más o menos ostentosa a ciertas realidades o símbolos del cristianismo. Es lo que sucede en el caso de Gonzalo de Córdoba o de su padre, el doctor Juan Martínez de Córdoba, llamado también Juan Martínez de Santa Cruz ${ }^{95}$. Lo mismo sucede con Juan Rodríguez de Santa Cruz. Tal vez estemos ante otro converso en el caso del bachiller Antón Martínez de Molina, en el de Alfonso Fernández de Medina y quizá en el del bachiller Juan Díaz de Torreblanca ${ }^{96}$. En realidad, todo ello no pasa de ser una mera suposición, aunque en algunos casos está bien provista de fundamento. En otros, por el contrario, la sospecha da paso a la evidencia. Así sucede con Maestro Pedro, uno de los varios que aparecen con ese nombre en la segunda mitad del siglo $\mathrm{XV}^{97}$. En 1485 fue condenado a muerte, junto con su mujer, Constanza Díaz, acusados de "herética pravedad", junto con otros dieciocho judeoconversos ${ }^{98}$. Parecido destino

\footnotetext{
${ }^{94}$ No se ha estudiado en España el papel desempeñado por los médicos en el gobierno y en la administración y pacificación de las ciudades. Sobre ese tema, referido a Italia hay un trabajo de gran interés: G. RugGiero, The Cooperation of Physicians and the State in the Control of Violence in Renaissance Venice, en "Journal of the History of Medicine and Allied Sciences", XXXIII (1978), pp. 156-166.

${ }^{95}$ AGS, RGS, fol. 63 , doc. de 1478 , mayo, 26. No sabemos si se trata del mismo personaje que con la denominación de "bachiller maestro Gonzalo, hijo de maestro Juan, físico y cirujano", encontramos en 1476 dando un poder para que arrendaran en su nombre unas casas que poseía en Gibraltar. Esa simple alusión a Gibraltar donde tantos conversos cordobeses se refugiaron inmediatamente después de las persecuciones de 1473 y 1474 es de por sí un testimonio más que elocuente sobre el grupo social al que pertenecía [AHPC, PN, 14-09(12), fol. 26 r., 1476, mayo, 5].

${ }^{96} \mathrm{La}$ relación más o menos directa con otros conversos o presuntos conversos se pone de manifiesto, por ejemplo, en los dos testamentos de Juan Díaz de Torreblanca, en cuyo entorno encontramos a personajes como Gonzalo de Chillón, Gonzalo Zamudio y otros, todos ellos sospechosos de pertenecer al grupo de los cristianos nuevos.

${ }^{97}$ Quizá es el mismo Pedro de Córdoba que encontramos actuando como testigo en un documento de 1468. AHPC, PN, 14-3, cuad. 2, fol. $139 \mathrm{v}$.

${ }^{98} \mathrm{El}$ testimonio está fechado el miércoles 7 de diciembre de 1485 , en las puertas de los alcázares de Córdoba, junto a la Torre del León, lugar y consistorio donde se realizaban habitualmente esos procesos. En esta ocasión fueron condenados por la misma causa, entre otros, Fernando González y Fernando de Alcaraz, escribanos públicos, e Isabel González, mujer de otro escribano público llamado Gonzalo de Alcaraz, quemado anteriormente. Ver AHPC, $\mathrm{PN}, 14-40(10)$, sin foliación. No fue el único de ese oficio y de ese nombre en tener problemas
} 
tuvo el varias veces citado Juan Rodríguez de Santa Cruz, que fue acusado igualmente de herejía ${ }^{99}$. Fue condenado igualmente el doctor Juan Martínez de Córdoba ${ }^{100}$. No conocemos bien en qué circunstancias fue ajusticiado, aunque con toda probabilidad el hecho tuvo lugar en 1483. Eso es lo que hace pensar un acta de los procolos otorgada el día 18 de agosto de ese año a través de la cual Diego González, como tutor, tomó posesión de unas casas en la collación de San Salvador, en nombre de Lope, Alfonso, Fernando, Gome e Isabel, menores, hijos del doctor Juan Martínez de Santa Cruz ${ }^{101}$. Por otra parte, de 27 de julio de 1484 data una merced hecha por los reyes a Pedro Ruiz de Morales de un oficio de jurado de Córdoba, que había quedado vacante por haber sido privado de él su titular, el físico Juan Martínez, a causa de sus prácticas judaizantes ${ }^{102}$. En cambio, su hijo, el bachiller en medicina Gonzalo de Córdoba, jurado de la collación de San Salvador, aparece como reconciliado en $1484^{103}$. En 1486 fue condenado otro médico llamado maestro Antón Rodríguez ${ }^{104}$. El propio maestro Rodrigo, junto con varios hermanos suyos, presumiblemente médicos igual que él, recibieron carta de seguro de los reyes ante los ataques que fustigó contra ellos un canónigo de Córdoba llamado Ximén López ${ }^{105}$.

La transmisión de los saberes médicos en el plano familiar es, como ya hemos visto, claramente comprobable estudiando algunas de las varias dinastías de físicos y cirujanos de Córdoba que es posible conocer a través

con la Inquisición. En las listas de "reconciliados" conservadas en el Archivo General de Simancas encontramos, entre los vecinos de la collación de S. Pedro, a "maestro Pedro, físyco, e Ysabel Fernández, su muger... reconçiliados, e él fijo de condenado, e seys fijos e fijas muchachos, nietos de condenado" (AGS, Contaduría Mayor de Cuentas, leg. 100, collación de S. Pedro). Seguramente se trata de un hijo homónimo del anterior.

${ }^{99}$ En 1487, los reyes confirmaban a Diego de Aguayo, veinticuatro de Córdoba, en la posesión de ciertas tiendas que compró al licenciado Juan Rodríguez de Santa Cruz, a pesar de la prohibición de tener tratos con herejes (AGS, RGS, 1487, abril, 4, Córdoba, fol. 11).

${ }^{100}$ M.A. LADERo Quesada, Los conversos de Córdoba en 1497, "El Olivo", XIII-29/30 (1989), p. 199, n ${ }^{\circ} 724$.

${ }^{101} \mathrm{AHPC}, \mathrm{PN}, 18-01(02)$, fol. 257 v. Uno de ellos, Gome, aparece luego como reconciliado. Ver ȦGS, $R G S$, 1484, febrero, 20, fol. 31. También: M.A. LADERo QuESADA, op. cit., p. $199 \mathrm{n}^{\mathrm{O}} 727$.

${ }^{102}$ AGS, $R G S$, fol. 19 del citado año.

${ }^{103}$ LADERO, op. cit., p. $199, \mathrm{n}^{\circ} 724$. 5.

${ }^{104}$ R. Gracia BolX, Autos de fe y causas de la Inquisición en Córdoba, Córdoba, 1983, p.

${ }^{105}$ En el documento citado aparecen como hermanos suyos Gonzalo de Córdoba, maestro Cristóbal y maestro Martín. AGS, RGS, fol. 308, 1480, marzo, 25, Toledo. 
de la documentación de protocolos. Se adivina en todos los casos la existencia de un aprendizaje directo, de padre a hijo (que a menudo se hace extensivo a varios hijos) a través de la mutua colaboración de ellos en el ejercicio profesional de la medicina. Algunas veces puede entreverse también no sólo la transmisión de esa experiencia de forma directa sino también indirecta, a través de los libros que un determinado médico deja a su muerte. Desgraciadamente nuestra información sobre ese tipo de legado testamentario es muy precaria en relación con los médicos del siglo XV pues son muy contados los casos de testamentos de médicos que hemos podido encontrar, en los cuales apenas hay alusiones verdaderamente útiles a los libros de medicina. Un ejemplo es el del bachiller Torreblanca, que hizo dos testamentos, en 1498 y en 1503. De ellos, sólo el segundo consigna la existencia de libros que, sin expresar el título de ellos, lega a su hijo Ruy Díaz especificando que le transmite tanto los "de Medeçina [como los] otros libros que él tiene"106. No nos informa mucho más el caso del cirujano Gómez Gutiérrez, que murió en diciembre de 1463. En el inventario de sus bienes aparecieron, junto a diez libros de física y cirugía escritos en papel, viejos y con sus coberturas blancas y coloradas, cuatro cuadernillos escritos en pliego de papel por encuadernar. Pero no conocemos sus títulos ni su contenido. Y el material al que se alude en el inventario relativo a su oficio de cirujano revela una simpleza extraordinaria pues se reducía a unas tijeras, paletas y otras cosas todas ellas contenidas en una bolsa de cuero ${ }^{107}$.

Hay un tema, no obstante, que aparece meridianamente claro a través de la documentación: la preferencia de los médicos de Córdoba por residir en las collaciones de la Ajarquía cordobesa. Estudiando con detenimiento las menciones que se hacen de las distintas collaciones en las que habitaban los médicos de Córdoba, resulta evidente la predilección por la parte oriental de la ciudad, la más activa, din duda. La mayoría de los datos se refieren a las de San Pedro, San Andrés, Santo Domingo, Santa María Magdalena, San Lorenzo y El Salvador, por ese orden. Y entre todas ellas, la primera, San Pedro destaca de forma tan ostensible que podemos afirmar con toda rotundidad que esa collación era el barrio de los médicos en Córdoba durante el siglo XV, los cuales se concentraban, dentro de ella, en las cercanías de la Corredera.

\footnotetext{
${ }^{106}$ AHPC, PN, 14-37(39), Cuad. 15, fols. 28 y 29, doc. de 1503, marzo, 1, Córdoba.

${ }^{107} \mathrm{AHPC}, \mathrm{PN}, 14-02(02), 405 \mathrm{r}$, doc de 1463, diciembre, s.d.
} 


\section{LOS EMPÍRICOS}

La relativa escasez de profesionales de la medicina junto con la demanda sanitaria explican la existencia de otro tipo de sanadores que, con una cualificación inferior $o$, incluso, sin ninguna cualificación especial, ejercían diferentes actividades médicas. La presencia de ese tipo de individuos se detecta en todas las ciudades de la época, y Córdoba no podía ser un caso aparte. Al margen de los físicos o cirujanos titulados por una universidad y de aquellos que, con o sin estudios universitarios, habían superado el correspondiente examen ante los alcaldes correspondientes, una muchedumbre de curanderos contribuían a paliar, a veces, algunas de las numerosas dolencias de la época. Las mujeres también desempeñaban a menudo ese cometido. Ya se ha aludido a la intervención que tuvo, en ese aspecto, el doctor Ribasaltas, médico de los reyes y alcalde examinador mayor, con el fin de impedir a una curandera judía de Carrión de los Condes que ejerciera ningún tipo de actividad médica para la que no estaba preparada ${ }^{108}$. Los médicos titulados consideraban siempre como intrusos a esos advenedizos, aunque no en todos los casos podemos decir que fueran meros charlatanes. Muchos de ellos practicaban determinadas especialidades médicas en las que raras veces intervenían los físicos y cirujanos. Incluso la mayoría de estos últimos - los cirujanos - no tenían, como hemos visto, una auténtica formación universitaria. Se ha sostenido que, sobre todo en la Corona de Aragón, los cirujanos estaban muchas veces asimilados a los barberos y, como ellos, tuvieron una consideración inferior a la de los verdaderos médicos, en parte debido a la opinión de que su oficio no era sino una más de las artes mecánicas ${ }^{109}$.

\footnotetext{
${ }^{108}$ AHPC, PN, 18-01(02), fol. 252 v.

${ }^{109} \mathrm{Granjel}$ refiere que, en un texto renacentista, el Viaje a Turquía, se establece una relación entre médico y cirujano comparándola con la que existe entre corregidor y verdugo: "hanse el médico y el cirujano como el corregidor y el verdugo, que sentencia: a éste den cien azotes a éste traigan a la vergüenza...; no lo quiere por sus manos él hazer, mándalo al verdugo... Pues así el médico ha de guiar al cirujano: corta este brazo, saja este otro, muda esta bizna [emplasto], limpia esta llaga, sangradle por que no corra allí la materia, poner este ungüento, engrosa esta mecha, dadle de comer esto y esto, en lo que mucho consiste la cura". L. GRANJEL, La medicina española renacentista, p. 72 y 221.
} 
Lo más característico de la época - aunque, en cierta medida, ha llegado incluso a nuestros días- es la abundancia de sanadores "empíricos", especializados en determinadas tareas, singularmente las quirúrgicas, en las que a veces cosechaban no pocos éxitos. Una de esas especialidades era la traumatología. En la época se la conocía con el nombre de "álgebra" y quienes la practicaban eran los algebristas, ensalmadores o "maestros de los quebrados". La iconografía de la época, sobre todo a partir de los siglos XV y XVI, nos muestra los artilugios mecánicos que usaban los traumatólogos para ayudarse en la cura de las dislocaciones o fracturas óseas ${ }^{110}$. Entre los algebristas de Córdoba del siglo XV, el primero de que tenemos noticia fue Alfonso Fernández Cardero. En 1467 recibió certificado de maestro Rodrigo, alcalde de los cirujanos de Córdoba, para poder ejercer su oficio $^{111}$. El acta que lo recoge nos dice que, con anterioridad, Alfonso Fernández había curado con éxito dislocaciones de brazos y piernas, razón por la cual recibió el correspondiente certificado. No obstante, maestro Rodrigo condicionaba esa licencia a que el beneficiario de la misma no se entrometiera en casos peligrosos o mortales, salvo "en compañía de un çirugiano auténtico", lo cual prueba que Alfonso Fernández no lo era propiamente. De todo ello se desprende no sólo la falta de estudios superiores para ejercer ese tipo de actividades - lo cual fue corriente entonces y después-, sino también el hecho de haberlas practicado, antes, incluso, de recibir licencia ${ }^{112}$. Es visible, por lo tanto, la escasez de titulados en medicina y cirugía, un hecho patente tanto en Córdoba como en otras ciudades. Torres Fontes se ha referido a los maestros que, sin haber sido examinados, ejercían la profesión en Murcia. Ese era el caso de Garcerán "el ensalmador", especialista en quebrados y en roturas óseas, que ejercía, además, de cirujano, sin haber hecho el examen. Le prohibieron actuar como cirujano, aunque se le permitió continuar en su oficio de ensalmador por su habilidad en "conponer fuesos"113. Y no era un ejemplo único. En Córdoba también está atestiguado un caso semejante en la persona de un albardero llamado Benito Sánchez "Quiebrabrazos" que, a juzgar por el único

\footnotetext{
${ }^{110}$ L. GRANJEL, op. cit., pp. 227 y ss.

"'AHPC, PN, 14-04(04), cuad. 8, fol. 27 r.

"12Todavía en la época de Felipe II, Fernando Mena, médico del rey, intentó, sin éxito, incorporar la traumatología al mundo de la cirugía. Ver: L. GRANJEL, La medicina española renacentista, p. 226.

${ }^{113}$ J. TORRES FONTES, op. cit. p. 226.
} 
testimonio que hemos conservado sobre él, se atrevía a intervenir en casos nada fáciles ${ }^{114}$. Otro algebrista de Córdoba fue maestro Enrique, vecino de la collación de S. Pedro. Apenas sabemos nada de él más que el nombre y la circunstancia curiosa de que era ciego, así como que murió en una posada Santa Cruz de Mudela en $1477^{115}$.

Cometido habitual de los empíricos era también, con frecuencia, la cura de hernias ${ }^{116}$. Entre los hernistas cordobeses del siglo XV encontramos al cirujano maestro Alfonso, que vivía en la collación de S. Pedro, tal vez el mismo de ese nombre que, siendo vecino de esa collación, vemos actuar en otras operaciones de distinta índole. Debía de tener una cierta fama fuera de la propia ciudad de Córdoba hasta el punto de atraer clientes de otras regiones pues en 1487 aparece estableciendo un acuerdo para curar la "rotura e quebradura" de la ingle que padecía un vecino de Ciudad Real llamado Pedro Ruiz de Molina ${ }^{17}$.

También solía estar en manos de los empíricos el tratamiento de las litiasis. A pesar de ello, la urología era campo habitual de médicos y cirujanos, algunos de los cuales escribieron, en el siglo XV, ciertos tratados básicos sobre el tema ${ }^{118}$. El único caso encontrado en la documentación cordobesa relativo a enfermedades urológicas estuvo encomendado a un empírico muy particular, Antón García de Orabuena, al cual nos referiremos más adelante, en relación con otro tipo de actuaciones médicas. En 1470 le vemos contratando con el hermano mayor de la Caridad de los Pobres de Córdoba la cura de una litiasis vesical que padecía uno de los acogidos a esta

\footnotetext{
${ }^{114}$ AHPC, 14-15(17), cuad. 10, fol. 5 v.

${ }^{115} \mathrm{AHPN}, \mathrm{PN}, 14-10(13)$, cuad. 14 , fol. 28 r. El documento nos informa que su viuda, Marina Fernández, dio poder a un tejedor de paños llamado Alfonso de Mora, con el fin de que pudiera recoger, en Santa Cruz de Mudela y en Valdepeñas, las pertenencias que dejó su marido al morir en el mesón de la primera de esas villas, y también para que pudiera traer a su nieto, Antón, el hijo de maestro Gonzalo. No nos es posible identificar a este último -hijo o, tal vez, yerno de maestro Enrique- con ninguno de los médicos de su mismo nombre.

${ }^{116}$ Sobre esta especialidad quirúrgica, ver: J. RIERA, Maestro Pedro, hernista sevillano del siglo XV, "IV Congreso Español de Historia de la Medicina. Actas", I, Granada, 1975, pp. 6162 y' V. EsCRIBANo GARCíA, La herniotomía en España en el siglo XVI. "Boletín de la Universidad de Granada", XI (55-56), Granada, 1939, pp. 379-90.

${ }^{117}$ AHPC, PN, 14-20(22), cuad. 8, fol. 11 r., 1487, noviembre, 26, Córdoba.

${ }^{118}$ Un tratado del siglo XV es el de Julián GuTIÉRREZ DE TOLEDo Cura de la piedra y dolor de la yjada y cólica renal, que fue impreso en 1498. Ver: L. GRANJEL, La medicina española renacentista, p. 238. Pese a todo, este mismo autor recuerda que el propio don Fernando de Antequera, para intentar curarse de una litiasis renal, recurrió a un empírico mallorquín. L. GRANJEL, La medicina española antigua y medieval, p. 153.
} 
institución de beneficiencia. La rotundidad con que está concebido el contrato, en el cual se especifican tanto los emolumentos -500 maravedíescomo el plazo de curación - seis meses- induce a pensar que aquella sociedad tenía medios para combatir con cierto éxito una dolencia como ésa ${ }^{119}$.

Campo igualmente en manos de los empíricos era el de los partos, atendidos por mujeres, las parteras, prácticas en un oficio que han seguido realizando habitualmente hasta bien entrado este siglo. Dos de las que ejercieron en Cordoba, llamadas Catalina Sánchez y Mencía Ferrández, se titularon "parteras de la reina", seguramente por haber atendido a la reina Isabel, que dio a luz en esta ciudad a su hija María, en $1482^{120}$.

Finalmente, estaban encomendadas también a los empíricos dos actividades que sólo ellos practicaban de forma habitual: las extracciones dentarias y las sangrías. Tanto una como otra cosa solían hacerla los barberos. Un testitmonio de 1498 nos ha facilitado la lista completa de barberos y sangradores (flebotomianos) de Córdoba, que eran veinticuatro, en total. Lo mismo que los médicos y cirujanos, los barberos tenían sus propios alcaldes y jueces examinadores ${ }^{121}$. Un documento de 1488 nos presenta a los alcaldes examinadores de barberos y flebotomianos dando licencia para ejercer el oficio a Gil Fernández, barbero, hijo de Fernando Alfonso de Vía, vecino de Fuenteovejuna. De ello se deduce que la autoridad de los alcaldes de los barberos de Córdoba se ejercía también -como es lógico pensar, por otra parte- en los núcleos de población dependientes de la capital ${ }^{122}$

En Córdoba y en la época a la que se refiere este trabajo existe una diferenciación clara entre el oficio de barbero y el de cirujano. Este último lo ejercen casi siempre personas que, además de ese título, asumen también el de físico. Por su parte, los barberos, sin perjuicio de que cumplieran a menudo funciones relacionadas directamente con la medicina - lo cual queda

\footnotetext{
${ }^{119}$ AHPC, PN, 14-06(06), cuad. 1, fol. 33 v.

${ }^{120}$ Una y otra aparecen con ese título en los protocolos cordobeses y a la primera, Catalina Sánchez de Montilla, la hemos detectado como beneficiaria de un juro de 12.000 mrs. anuales. Ver AGS, CMC $1^{\text {a }}$ época, leg. 191, 1492. A la segunda la encontramos realizando un préstamo de $2.000 \mathrm{mrs}$. a un artesano de la ciudad (AHPC, PN, 14-22(24), fol. 115, 1492, abril, 30). Sobre el nacimiento de esa infanta, ver E. FLóREZ, Memorias de las reinas católicas de España, Madrid, Aguilar, 1964, p. 388.

${ }^{121} \mathrm{AHPC}, 14-34$, cuad. 7, fol. 19 r, doc. de 1498, marzo, 13, Córdoba.

${ }^{122} \mathrm{AHPN}, \mathrm{PN}, 14-21(23), 12,31 \mathrm{v}$.
} 
subrayado incluso a través del parentesco que algunos de ellos tenían con médicos y cirujanos, como si todo ello fuera una especie de tradición familiar-, parecen, no obstante, haberse dedicado esencialmente a lo que era su oficio habitual de afeitar. Un contrato de arrendamiento de su tienda situada en la Corredera que hizo, en 1484, el barbero maestro Alfonso, hijo del físico y cirujano maestro Lope y hermano del también físico y cirujano maestro Juan, revela que los utensilios traspasados tenían más relación con las funciones más habituales de un barbero que con cualquier otro cometi$\mathrm{do}^{123}$.

Un capítulo de gran interés es el que se refiere a las prácticas supersticiosas, mágicas o hechiceriles en el intento de curación de determinadas dolencias. En la época, algunas de esas prácticas se tenían por cosa habitual respecto de ciertas enfermedades concretas. Así sucedía, por ejemplo, con la rabia, cuya curación se intentaba conseguir con el auxilio de los llamados saludadòres, respecto de los cuales circulaba la creencia de que poseían poderes especiales para neutralizar esa enfermedad, de una gravedad extrema. Todavía en pleno siglo XVI, personas eminentes, como el cronista y cosmógrafo Pedro Mexía, atribuían ese poder a los saludadores entendiendo que poseían una "virtud provechosa contra la ponzoña de los perros rabiosos"124. A finales del siglo XV ejercía esa función de saludador en Córdoba un personaje llamado Juan Sánchez de Castro, vecino de la collación de la Magdalena e hijo de otro saludador del mismo nombre ${ }^{125}$. Los testimonios que han llegado hasta nosotros sobre su actividad permiten forjarse alguna idea sobre la forma de actuar de estos curiosos personajes. Los contemporáneos, aunque estaban muy lejos de conocer el origen microbiano de muchas de las enfermedades, entre ellas la rabia, eran

\footnotetext{
${ }^{123} \mathrm{El}$ documento dice que maestro Alfonso, barbero, hijo de maestro Lope, vecino en San Pedro, acuerda con su hijo Lope, barbero, y con Alfonso de Alcaraz, también barbero, que el dicho maestro Alfonso acoge a los sobredichos en una tienda que él tiene en la Corredera y les da cuatro bancas, dos escalfadores, ocho paños nuevos grandes, ocho paños nuevos pequeños, tres sillas de espaldas, dos sillas de costillas, una olla de cobre con su tapadera de cobre, un "baçanero", un banco, una muela de piedra con una pileta, para afilar, un banco con su torno de hierro, una bigornia pequeña, un destajo, dos verjas de hierro y una tabla con las armas para que por ello le den cada semana $50 \mathrm{mrs}$. en concepto de alquiler desde la fecha del contrato hasta el día de San Juan próximo. El dicho maestro Alfonso podrá usar de su oficio en la dicha tienda $\mathrm{y}$, al final del tiempo, deberán entregarle todos los utensilios citados. Si falta algo, deberán pagarlo. AHPC, PN, 14-15(17), fol. 33 v., doc. de 1484, febrero, 23.

${ }^{124} \mathrm{~L}$. GRANJEL, La medicina española renacentista, p. 139. En relación con este tema, ver el estudio de J. TORRES FONTES, El saludador, en "Homenaje a José Ballester", Murcia, 1973.

${ }^{125} \mathrm{AHPC}, \mathrm{PN}, 14-30(32)$, cuad. 4 , fols. 12 r. y $13 \mathrm{v}$.
} 
conscientes de la existencia, a grandes rasgos, de lo que hoy llamamos el período de incubación de ellas. Y era precisamente en ese período -en el cual actuaba lo que ellos creían que era una "ponzoña" inoculada por el perro rabioso - cuando se producía la actuación del saludador. A juzgar por los éxitos que, al parecer, conseguían estos últimos habría que preguntarse si los contemporáneos juzgaban como rabioso a todo perro agresivo que mordía a otros animales o al hombre. En realidad, los propios testimonios sobre supuestas curaciones suelen insistir en la extraordinaria agresividad de los perros implicados en los casos referidos y ofrecen pruebas de ello que abonan la hipótesis de que, en efecto, los perros agresores padecían la enfermedad. Las supuestas curaciones se explican, en gran medida, como consecuencia de la relativamente baja incidencia de la rabia en las personas mordidas, que, según hoy sabemos, no llega a alcanzar el 20 por ciento de los casos.

Pero dejando a un lado el carácter ritual que tenían, con frecuencia, las prácticas médicas, la documentación coetánea nos ofrece otras manifestaciones del ejercicio de la medicina que resultan difíciles de definir e, incluso, de entender adecuadamente. Hay un caso concreto, muy bien documentado, que no sabemos si tal vez debería contemplarse en el marco del curanderismo y que presenta connotaciones muy especiales. Tenemos en torno a él varios documentos todos los cuales se refieren al año $1465^{126}$ y hacen alusión a un personaje llamado Antón García de Orabuena, al que definen como "maestro de los çaratanes e otras curas e enfermedades yncurables"127.

El zaratán es el cáncer de mama y, en efecto, encontramos al maestro Orabuena actuando en la cura de mujeres que padecían esa enfermedad, sobre cuyos efectos los documentos ofrecen una información muy precisa. De los casos descritos, uno de ellos resulta bastante sorprendente. La protagonista se llamaba Catalina Ferrández Montesdoca. Era sevillana y esposa de Alvar Díaz de Villacruces, escribano mayor del oficio del conde de Plasencia, Alvaro de Estúñiga. El documento nos ofrece el testimonio de

\footnotetext{
${ }^{126}$ Está documentado, no obstante, como maestro de zaratanes, hasta más tarde. El último documento que hemos encontrado referente a él data de 1475 (AHPC, PN, 14-08(11), 8, 3 r., 1475, mayo, 29).

${ }^{127} \mathrm{AHPC}, \mathrm{PN}, 14-03(03)$, cuad. 1, fol. 83 r.-v., 84 r. y v. y 111 r. y v. Un ejemplo de curanderismo en época posterior es el estudiado por A. GonZÁLEZ PALENCIA, El curandero morisco del siglo XVI, Román Ramírez, en "Leyendas e Historia", Madrid, 1942, pp. 215-284.
} 
la enferma, que dice fue víctima de un zaratán en un pecho, donde le había crecido el tumor, "del tamaño como la cabeça de criatura de medio año" ${ }^{128}$. Consultó al respecto a varios médicos de Sevilla, entre ellos el propio físico del duque de Medina Sidonia, Juan Rodríguez, el cual opinó "que sy ella de la dicha ynfermedat sanase, que él dexaría de usar de su ofiçio e quemaría sus libros que tenía de la medeçina". Ante esa perspectiva, la enferma se trasladó a Córdoba para ponerse en manos de Antón García de Orabuena, que tenía fama de haber tratado con éxito semejantes enfermedades. Y todo ello para terminar confesando que, después de un tratamiento de unos cuatro meses, ella se sentía "en sy ser sana e fuera de todo peligro e en buena dispusiçión" ${ }^{129}$.

No sabemos cuánto había de verdad en todo ello y cuánto de convicción en la paciente. Otro caso de los descritos tiene apariencias más dramáticas. Se refiere a una enferma llamada Inés Ferrández, mujer de Gómez Ferrández de Santa Eufemia, vecina de Córdoba. El acta de protocolos describe su cuadro clínico diciendo que le había salido un zaratán en su pecho izquierdo del cual le habían curado varios físicos, que cita, hasta que se decidió a acudir a Antón García. Este, considerando el aspecto que presentaba y el hecho de habérsele extendido hasta la axila, se limitó a dejar constancia de la gravedad de la dolencia y a declinar cualquier responsabilidad en el desenlace fatal que de todo ello podía esperarse ${ }^{130}$.

Ante un testimonio como el anterior, cabe pensar que la actividad de un personaje como Antón García de Orabuena debía de limitarse, en la mayoría de los casos, a paliar los efectos de una enfermedad que era mortal

\footnotetext{
${ }^{128} \mathrm{El}$ documento especifica que "la dicha Catalina Ferrández, a pedimiento del dicho Antón Garçía, dixo que a ella le nasçió en la su teta derecha, estando en la dicha çibdat de Seuilla, un çaratán tamaño como la cabeça de criatura de un año, del qual dicho çaratán non falló en la dicha çibdat maestro que dello usase cura, diziendo que era cosa mortal porque estaua en tan grant cresçimiento que sy ge lo ouieran de sacar que luego auíe de morir, como quier que el doctor Iohán Rodríguez, físico del duque, e su ermano, Alfonso Rodríguez, e otros muchos famosos físicos de la dicha çibdat la vieron e que aun dixo el dicho doctor Iohán Rodríguez, físico del dicho duque, que sy ella de la dicha ynfermedat sanase que él dexaría de usar de su ofiçio e quemaría sus libros que tenía de la medeçina. Pero dixo que ella vino a esta çibdat para que curase della el dicho Antón Garçía porque auíe oydo dezir en la dicha çibdat de Seuilla que auíe curado de las semejantes ynfermedades a muy muchas personas e las auíe sanado. El qual dize que puede auer quatro meses que cura della e por quanto ella syente en sy ser sana e fuera de todo peligro e en buena dispusiçión, que se quiere yr e boluer a su casa a la dicha çibdat de Seuilla, de lo qual pidió testimonio el dicho Antón Garçía de Orabuena" [AHPC, PN, 1403(03), cuad. 1, fol. $111 \mathrm{r}$.].

${ }^{129} \mathrm{Ibidem}$.

${ }^{130} \mathrm{AHPC}, \mathrm{PN}, 14-03(03)$, cuad. 1, fol. $84 \mathrm{r}$ y v.
} 
de necesidad, o poco menos, prodigando cuidados que aliviaran, de alguna forma, los inevitables sufrimientos de las personas que la padecían. Pero hay otro testimonio referido a él que pone de manifiesto un éxito evidente del "maestro de zaratanes": la curación de un sobrehueso - otro tipo de tumorque le había salido en la frente a una paciente llamada Ana Ferrández, del cual la curó "en obra de quinse días, e le quedó la frente toda igual, el qual era de tamaño como una castaña"131.

En el acta notarial, la enferma curada testifica que "la primera medeçina e cura que le mandó faser fue que se confesase e comulgase e mandase desir una misa ante el altar de Santa María"132. Como muchos otros curanderos que ha habido, incluso en tiempos recientes, Antón García de Orabuena confiaba, sobre todo, en el auxilio de la Providencia, absolutamente necesario para obtener éxito en una tarea tan difícil como era la suya $^{133}$.

\section{RÉSUMÉ}

De par sa condition de capitale du Califat, Cordoue fut, pendant le Haute Moyen Âge, la ville des échanges culturels par excellence. C'est de là qu'a été diffusé, dans une large mesure, le savoir antique et, avec lui, la connaisance de la science médicale. Mais ce travail se centre plutôt sur la situation de la médecine cordouane au $\mathrm{XV}^{\mathrm{e}}$ siècle et se base essentiellement sur les renseignements qui nous sont parvenus à travers les documents fournis par les actes notariaux. Grâce à eux, l'on connaît certains détails sur le traitement des maladies et sur la diffusion des connaissances médicales. Ces documents mettent en évidence le grand nombre de médecins d'origine juive qu'il y avait à l'époque et soulignent l'importance de la tradition familiale en tant que moyen de transmission des dites connaissances.

\footnotetext{
${ }^{131}$ AHPC, PN, 14-03(03), cuad. 1, fol. $111 \mathrm{v}$.

${ }^{132}$ Ibídem.

${ }^{133} \mathrm{De}$ todas formas, parece que era una costumbre establecida entre los sanadores hacer confesar a los enfermos graves antes de proceder a cualquier intervención médica, a fin de asegurarse de la salvación de su alma ante cualquier fallo que pudiera producirse como consecuencia de su actuación. Así se estipuló, por ejemplo, en Valencia, en 1330. Ver L. GarCía BALleSTER, La Medicina, en "Historia de España" dirigida por D. Ramón Menéndez Pidal, vol. XVI, p. 612.
} 


\section{SUMMARY}

On account of its position as the capital of the Caliphate, Córdoba was, during the Middle Ages, an ideal city for cultural interchange. From there, the ancient wisdom was, in large measure, spread as well as the medical science of the time. However this paper is focused on the situation of the medicine in Cordoba in the 15th century. It is essentially based on the information drawn from the notarial documentation. In theses sources we come to know details related to the treatment of illness and the diffusion of medical knowledge. The paper draws attention to the abundance of doctors of Jewish origin as well as the importance of family tradition as a means of transmission of medical learning. 